\title{
Trends in Stroke Presentations before and during the COVID-19 Pandemic: A Meta-Analysis
}

\author{
Noman Ishaque, ${ }^{\mathrm{a}}$ Asif Javed Butt, ${ }^{\mathrm{a}}$ Joseph Kamtchum-Tatuene, ${ }^{\mathrm{b}}$ Ali Zohair Nomani, ${ }^{\mathrm{a}, \mathrm{c}}$ Sarah Razzaq, \\ Nida Fatima, ${ }^{\mathrm{e}}$ Chetan Vekhande, ${ }^{\mathrm{a}}$ Radhika Nair, ${ }^{\mathrm{a}}$ Naveed Akhtar, ${ }^{\mathrm{f}}$ Khurshid Khan, ${ }^{\mathrm{a}}$ Maher Saqqur, \\ Ashfaq Shuaib $^{\text {a }}$ \\ ${ }^{a}$ Division of Neurology, Department of Medicine, University of Alberta, Edmonton, $A B$, Canada \\ ${ }^{b}$ Neuroscience and Mental Health Institute, Faculty of Medicine and Dentistry, University of Alberta, Edmonton, AB, Canada \\ ${ }^{\mathrm{C}}$ Red Deer Regional Hospital Center, Red Deer, AB, Canada \\ ${ }^{\mathrm{d}}$ Department of Medicine, Fatima Jinnah Medical University, Lahore, Pakistan \\ eDepartment of Neurosurgery, Massachusetts General Hospital, Harvard Medical School, Boston, MA, USA \\ fDivision of Neurology, Department of Medicine, Hamad General Hospital, Doha, Qatar \\ ${ }^{9}$ Department of Neurology, Trillium Health Care, University of Toronto, Mississauga, ON, Canada
}

Background and Purpose There are reports of decline in the rates of acute emergency presentations during coronavirus disease 2019 (COVID-19) pandemic including stroke. We performed a meta-analysis of the impact of COVID-19 pandemic on rates of stroke presentations and on rates of reperfusion therapy.

Methods Following the Meta-analysis Of Observational Studies in Epidemiology (MOOSE) guidelines, we systematically searched the literature for studies reporting changes in stroke presentations and treatment rates before and during the COVID-19 pandemic. Aggregated data were pooled using meta-analysis with random-effect models.

Results We identified 37 observational studies $(n=375,657)$. Pooled analysis showed decline in rates of all strokes (26.0\%; 95\% confidence interval [Cl], 22.4 to 29.7) and its subtypes; ischemic (25.3\%; 95\% Cl, 21.0 to 30.0), hemorrhagic (27.6\%; 95\% Cl, 20.4 to 35.5), transient ischemic attacks (41.9\%; 95\% Cl, 34.8 to 49.3 ), and stroke mimics (45.6\%; $95 \% \mathrm{Cl}, 33.5$ to 58.0 ) during months of pandemic compared with the pre-pandemic period. The decline was most evident for mild symptoms (40\% mild vs. 25\%-29\% moderate/severe). Although rates of intravenous thrombolytic (IVT) and endovascular thrombectomy (EVT) decreased during pandemic, the likelihood of being treated with IVT and EVT did not differ between the two periods, both in primary and in comprehensive stroke centers (odds ratio [OR], 1.08; 95\% $\mathrm{Cl}, 0.94$ to 1.24 and $\mathrm{OR}$, $0.95 ; 95 \% \mathrm{Cl}, 0.83$ to 1.09 , respectively).

Conclusions Rates of all strokes types decreased significantly during pandemic. It is of paramount importance that general population should be educated to seek medical care immediately for stroke-like symptoms during COVID-19 pandemic. Whether delay in initiation of secondary prevention would affect eventual stroke outcomes in the long run needs further study.
Correspondence: Ashfaq Shuaib Division of Neurology, Department of Medicine, University of Alberta, Edmonton T6G 2G3, AB, Canada Tel: $+1-780-248-1660$

Fax: +1-780-248-1807

E-mail: shuaib@ualberta.ca https://orcid.org/0000-0002-3380-7068

Received: May 2, 2021

Revised: August 15, 2021 Accepted: September 5, 2021

Keywords Stroke; COVID-19; Hospitalization; Fibrinolysis; Thrombectomy; Meta-analysis 


\section{Introduction}

Coronavirus disease 2019 (COVID-19) infection was initially reported from Wuhan, China in December 2019.' It was declared a pandemic by World Health Organization in March $2020{ }^{2}$ There was a significant decrease in the hospital presentations and admissions, reported for most medical emergencies, including trauma, surgical emergencies, stroke, and acute coronary syndromes (ACSs) in regions with high numbers of COVID-19 cases $^{3-6} \mathrm{~A}$ decrease in stroke admissions during the first peak of the pandemic was reported from Asia, Europe, North and South America. ${ }^{7-14}$ While the decrease was predominantly recorded for those with milder symptoms, presentation for all stroke subtypes decreased substantially. This was suggested by decrease in the utilization of the computed tomography perfusion based rapid processing of perfusion and diffusion (RAPID, iSchemaView, Redwood City, CA, USA) software for acute stroke imaging in a report from USA., 8,13,15-17

The decrease in stroke admissions reported during the COVID-19 pandemic; however, has not been uniform, with conflicting reports from across the globe. ${ }^{18}$ In addition, late presentation as reported by few has raised concerns that the pandemic may result in fewer patients receiving thrombolysis or endovascular thrombectomy (EVT). ${ }^{19}$ Several factors may have contributed to the recorded decrease in rates of stroke admissions and should be reviewed with caution. ${ }^{20-24}$ Studies that provide information based on prospective registries or databases are more likely to offer accurate analysis of the changes developing during the pandemic. Reports comparing the change noticed during the pandemic to retrospectively collected pre-pandemic data tend to be less accurate and should be reviewed with caution. In view of above, a meta-analysis of the published reports may help establish the link between the impact of the COVID-19, rates of stroke admissions, rates of treatment with reperfusion therapy and likelihood of being treated with reperfusion therapy. We performed a systematic review and meta-analysis of observational studies during the COVID-19 pandemic between January 2020 and July 2021. We analyzed the data to answer following questions: (1) Was there a decrease in the rates of stroke hospitalization? (2) If a decrease in stroke rates was evident, was this specific to any particular stroke type (ischemic, hemorrhagic, transient ischemic attack [TIA]) and/or any National Institutes of Health Stroke Scale (NIHSS)-based severity (mild, moderate, severe)? (3) What was the effect of the pandemic on rates of thrombolysis and EVT?

\section{Methods}

\section{Data sources and study selection}

The data supporting the findings of study are available from the corresponding author upon reasonable request. The PubMed and Embase databases were systematically searched from January 1st, 2020, until July 24th, 2021, for studies published in English. We used a combination of the following terms for the database search: "Stroke," "Cerebrovascular accidents," "COVID-19," "Coronavirus Disease 2019." Details of the search strategy can be found in Supplementary Table 1. The current meta-analysis is compliant with the Preferred Reporting Items for Systematic Review and Meta-analysis (PRISMA) statement. ${ }^{25}$

Two authors (N.I. and A.J.B., both neurologists) independently screened the study titles and abstracts after removal of duplicates. Articles identified as potentially fulfilling our inclusion criteria underwent full-text evaluation by four authors (N.I., A.J.B., C.V., and R.N., all neurologists). We included studies only if they were original reports or observational studies with information on the rates of stroke cases and hospitalization before and during the COVID-19 pandemic. We excluded studies that did not provide information on the pre-COVID-19 stroke rates or were reviews without original data.

\section{Data extractions and quality assessment}

Publication quality was assessed using the Newcastle-Ottawa Quality assessment scale for cohort studies. ${ }^{26}$ This scale is used to assess the Participant Selection, Comparability, and Outcome. A 'good quality' publication was defined as having 3 or 4 stars in selection domain and 1 or 2 stars in comparability domain and 2 or 3 stars in outcome domain. 'Fair quality' was defined as having 2 stars in selection domain and 1 or 2 stars in compatibility domain and 2 or 3 stars in outcome domain. 'Poor quality' was defined as having 0 or 1 star in selection domain or 0 stars in comparability domain or 0 or 1 stars in outcome domain. We only included studies that were of 'good or fair quality'.

N.I., A.J.B., C.V., and R.N. extracted relevant data using a standardized data extraction form. Any disagreements were resolved by discussion. Extracted data included name of first author, year of publication, geographical location of the study, rate of total strokes, rate of ischemic strokes, hemorrhagic strokes, TIAs, stroke mimics, onset to door times (mean \pm standard deviation [SD]), classification of stroke center (primary or comprehensive stroke center), rates of reperfusion therapies, and severity of stroke based on NIHSS scores (mean \pm SD at presentation and number of mild [NIHSS $<5]$, moderate [NIHSS of 
5-15], and severe [NIHSS >15] strokes) before and during the pandemic. Wherever the mean \pm SD of NIHSS or onset-to-door time were not reported, they were estimated from the median and interquartile range. ${ }^{27}$ Reperfusion therapy was defined as intravenous thrombolysis or EVT.

\section{Statistical analysis}

We used meta-analysis with random effects models to pool the percent change in the number of various stroke presentations (ischemic, hemorrhagic, TIA, stroke mimic, mild, moderate, severe) and the likelihood of receiving treatment with intravenous thrombolysis or thrombectomy across studies. For studies reporting the onset-to-door time, we pooled the standardized mean difference between the pre-pandemic and the pandemic period. Publication bias was assessed by inspecting funnels plots and performing the Egger test. Heterogeneity between studies and subgroups was assessed using the chi-square test on the Cochran $\mathrm{O}$ statistic and quantified by the $\mathrm{I}^{2}$ index. All analyses were performed with STATA version 17.0 (StataCorp., College Station, TX, USA). All tests were 2-tailed and unpaired with a significance threshold of $P \leq 0.05$.

\section{Results}

The systematic database search retrieved 4,853 records, which were screened, and 116 studies underwent full-text evaluation. After excluding 79 studies for reasons outlined in Figure 1, 37 studies with 375,657 patients, meeting 'fair or good' quality criteria were selected for further analysis. ${ }^{8,28-63}$ Twenty-four studies met criteria for 'good' quality and 13 met criteria for 'fair' quality (Supplemetary Tables 2-4). Most studies compared the pandemic period (ranging from January to June 2020) to a similar period in the preceding year (range January to June 2019) ${ }^{28-31,33,35,39,41-43,45,46,48-50,52,54-58,60}$ or the months preceding the pandemic (range September 2019 to December 2019). $8,32,34,36-38,40,44,47,51,53,59,61-63$

\section{Rates of stroke admissions and severity of symptoms}

There was decline in rates of stroke admissions during the pandemic. The rate of all types of stroke presentations during pandemic was $26.0 \%$ lower than during pre-pandemic period (95\% confidence interval $[\mathrm{Cl}], 22.4$ to 29.7 ) as shown in Table 1 and Figure 2. There was a publication bias with smaller studies reporting larger percent changes (Egger intercept=3.8; $P=0.02$ ) (Table 1 and Supplementary Figure 1). Analysis by stroke types showed that both ischemic and hemorrhagic

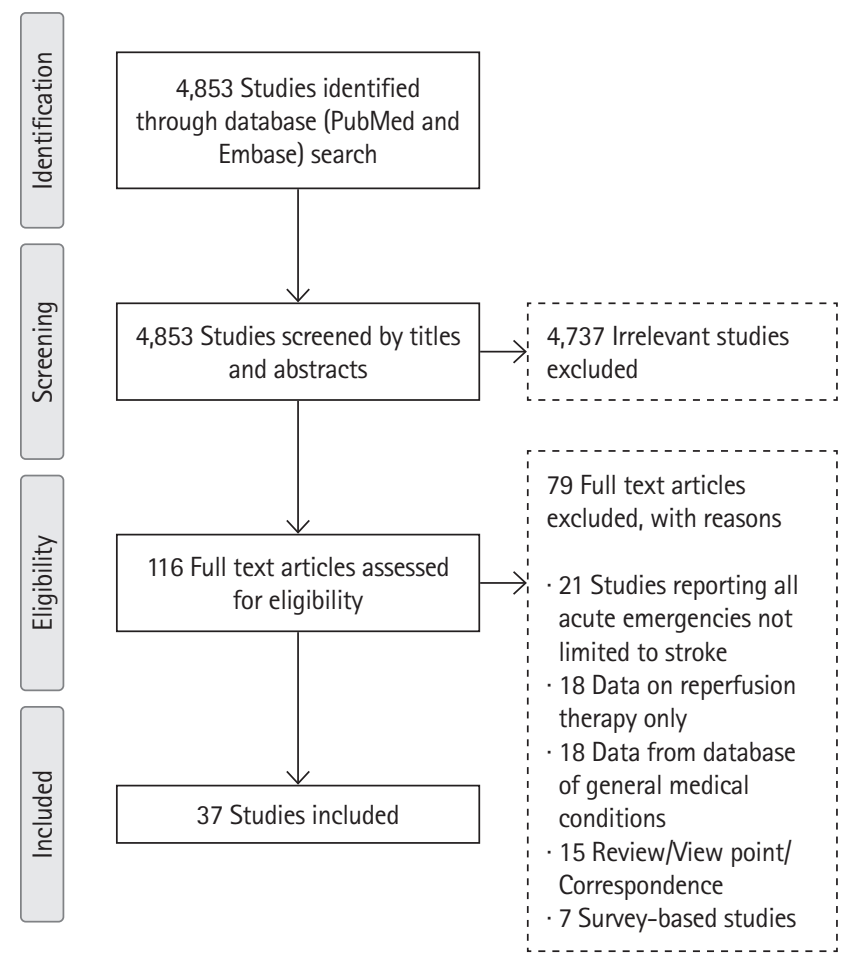

Figure 1. Preferred Reporting Items for Systematic Reviews and Meta-Analysis (PRISMA) flow diagram of the observational studies selection process.

stroke presentation rates decreased during the pandemic (Table 1). Specifically, the rate of ischemic stroke presentations during pandemic was 25.3\% lower than during the pre-pandemic pe$\operatorname{riod}(95 \% \mathrm{Cl}, 21.0$ to 30.0 ) (Figure 3) while the rate of hemorrhagic stroke presentations during the pandemic was 27.6\% lower (95\% Cl, 20.4 to 35.5) (Figure 4). Additionally, rates of TIAs and stroke mimics declined by $41.9 \%(95 \% \mathrm{Cl}, 34.8$ to 49.3) (Supplementary Figure 2) and $45.6 \%(95 \% \mathrm{Cl}, 33.5$ to 58.0) (Supplementary Figure 3), respectively.

Subgroup analysis revealed that there was a decrease in stroke rates during the pandemic for all severity categories with mild strokes (percent change, $40.2 ; 95 \% \mathrm{Cl}, 21.7$ to 60.2 ) (Supplementary Figure 4) being the most affected (Table 1) as compared with moderate (percent change, 25.6; 95\% Cl, 11.0 to 43.8) (Supplementary Figure 5) and severe strokes (percent change, $29.1 ; 95 \% \mathrm{Cl}, 17.4$ to 42.4 ) (Supplementary Figure 6). Regarding the distribution of mild, moderate, and severe strokes, there was an overall decrease in the share of mild strokes and a corresponding increase in the share of moderate and severe strokes (Supplementary Figures 7-9). During the pandemic, the odds for admitting a mild stroke versus a moderate or severe stroke was $0.78(95 \% \mathrm{Cl}, 0.67$ to 0.90 ; $1^{2}=73.5 \%$ ) (Supplementary Figure 7). 
Table 1. Percent decrease in the number of strokes by type, region, and severity

\begin{tabular}{|c|c|c|c|c|c|c|}
\hline \multirow{2}{*}{ Region } & \multirow{2}{*}{ Studies } & \multirow{2}{*}{ Percent change $(95 \% \mathrm{Cl})$} & \multicolumn{2}{|c|}{ Heterogeneity assessment } & \multicolumn{2}{|c|}{ Egger test for publication bias } \\
\hline & & & $1^{2}$ & $P$ & Intercept & $P$ \\
\hline \multicolumn{7}{|l|}{ All strokes } \\
\hline Overall & 37 & $26.0(22.4-29.7)$ & 99.6 & $<0.001$ & 3.8 & 0.02 \\
\hline Asia & 7 & $39.9(32.7-47.4)$ & 96.9 & $<0.001$ & -3.4 & 0.262 \\
\hline Europe & 19 & $20.5(17.9-23.3)$ & 97.3 & $<0.001$ & 0.5 & 0.47 \\
\hline Northern America & 10 & $29.2(16.7-43.5)$ & 99.8 & $<0.001$ & 6.4 & 0.13 \\
\hline Global & 1 & $11.5(11.3-11.7)$ & NA & NA & NA & NA \\
\hline \multicolumn{7}{|l|}{ Ischemic strokes } \\
\hline Overall & 34 & $25.3(21.0-30.0)$ & 99.4 & $<0.001$ & 2.7 & 0.02 \\
\hline Asia & 7 & $40.8(33.3-48.5)$ & 95.8 & $<0.001$ & -1.3 & 0.58 \\
\hline Europe & 18 & $17.8(15.4-20.4)$ & 96.2 & $<0.001$ & 0.27 & 0.65 \\
\hline Northern America & 9 & $29.9(16.8-44.9)$ & 99.7 & $<0.001$ & 6.9 & 0.10 \\
\hline \multicolumn{7}{|l|}{ Hemorrhagic strokes } \\
\hline Overall & 24 & $27.6(20.4-35.5)$ & 98.1 & $<0.001$ & 1.9 & 0.25 \\
\hline Asia & 6 & $31.0(11.2-55.2)$ & 98.0 & $<0.001$ & -1.8 & 0.60 \\
\hline Europe & 12 & $25.6(18.8-33.0)$ & 93.7 & $<0.001$ & 1.1 & 0.06 \\
\hline Northern America & 6 & $25.8(10.9-44.1)$ & 98.1 & $<0.001$ & 3.6 & 0.13 \\
\hline \multicolumn{7}{|c|}{ Transient ischemic attacks } \\
\hline Overall & 22 & $41.9(34.8-49.3)$ & 96.4 & $<0.001$ & 1.8 & 0.001 \\
\hline Asia & 3 & $51.5(47.1-56.0)$ & NA & NA & -0.3 & 0.77 \\
\hline Europe & 15 & $38.3(30.9-45.9)$ & 93.3 & $<0.001$ & 1.3 & 0.005 \\
\hline Northern America & 3 & $49.9(17.5-82.3)$ & 98.5 & $<0.001$ & 3.2 & 0.40 \\
\hline \multicolumn{7}{|l|}{ Stroke mimics } \\
\hline Overall & 8 & $45.6(33.5-58.0)$ & 95.9 & $<0.001$ & 2.5 & 0.40 \\
\hline Asia & 2 & $52.8(47.5-58.1)$ & NA & NA & NA & NA \\
\hline Europe & 5 & $39.7(29.2-50.7)$ & 92.7 & $<0.001$ & 2.7 & 0.40 \\
\hline Northern America & 1 & $78.1(68.9-85.2)$ & NA & NA & NA & NA \\
\hline \multicolumn{7}{|l|}{ Stroke with NIHSS $<5$} \\
\hline Overall & 9 & $40.2(21.7-60.2)$ & 99.7 & $<0.001$ & 6.8 & 0.21 \\
\hline Asia & 5 & $54.4(46.6-62.1)$ & 93.2 & $<0.001$ & 0.8 & 0.82 \\
\hline Europe & 2 & $6.9(6.0-7.8)$ & NA & NA & NA & NA \\
\hline Northern America & 2 & $50.4(48.3-52.6)$ & NA & NA & NA & NA \\
\hline \multicolumn{7}{|c|}{ Stroke with NIHSS 5-15 } \\
\hline Overall & 8 & $25.6(11.0-43.8)$ & 98.9 & $<0.001$ & 2.4 & 0.32 \\
\hline Asia & 5 & $32.9(20.6-46.5)$ & 93.9 & $<0.001$ & -1.8 & 0.3 \\
\hline Europe & 2 & $-6.6(5.5-7.7)^{*}$ & NA & NA & NA & NA \\
\hline Northern America & 1 & $33.8(27.8-40.4)$ & NA & NA & NA & NA \\
\hline \multicolumn{7}{|l|}{ Stroke with NIHSS >15 } \\
\hline Overall & 9 & $29.1(17.4-42.4)$ & 97.1 & $<0.001$ & 2.0 & 0.26 \\
\hline Asia & 5 & $33.8(18.7-50.8)$ & NA & NA & -0.8 & 0.70 \\
\hline Europe & 2 & $12.4(10.4-14.5)$ & NA & NA & NA & NA \\
\hline Northern America & 2 & 30.1 (26.4-33.9) & NA & NA & NA & NA \\
\hline
\end{tabular}

$\mathrm{Cl}$, confidence interval; NA, not available, the statistic cannot be computed due to the small number of studies ( $\mathrm{n} \leq 3$ ); NIHSS, National Institutes of Health Stroke Scale.

*There was an increase in the number of moderate strokes in Europe which explains the minus sign. 


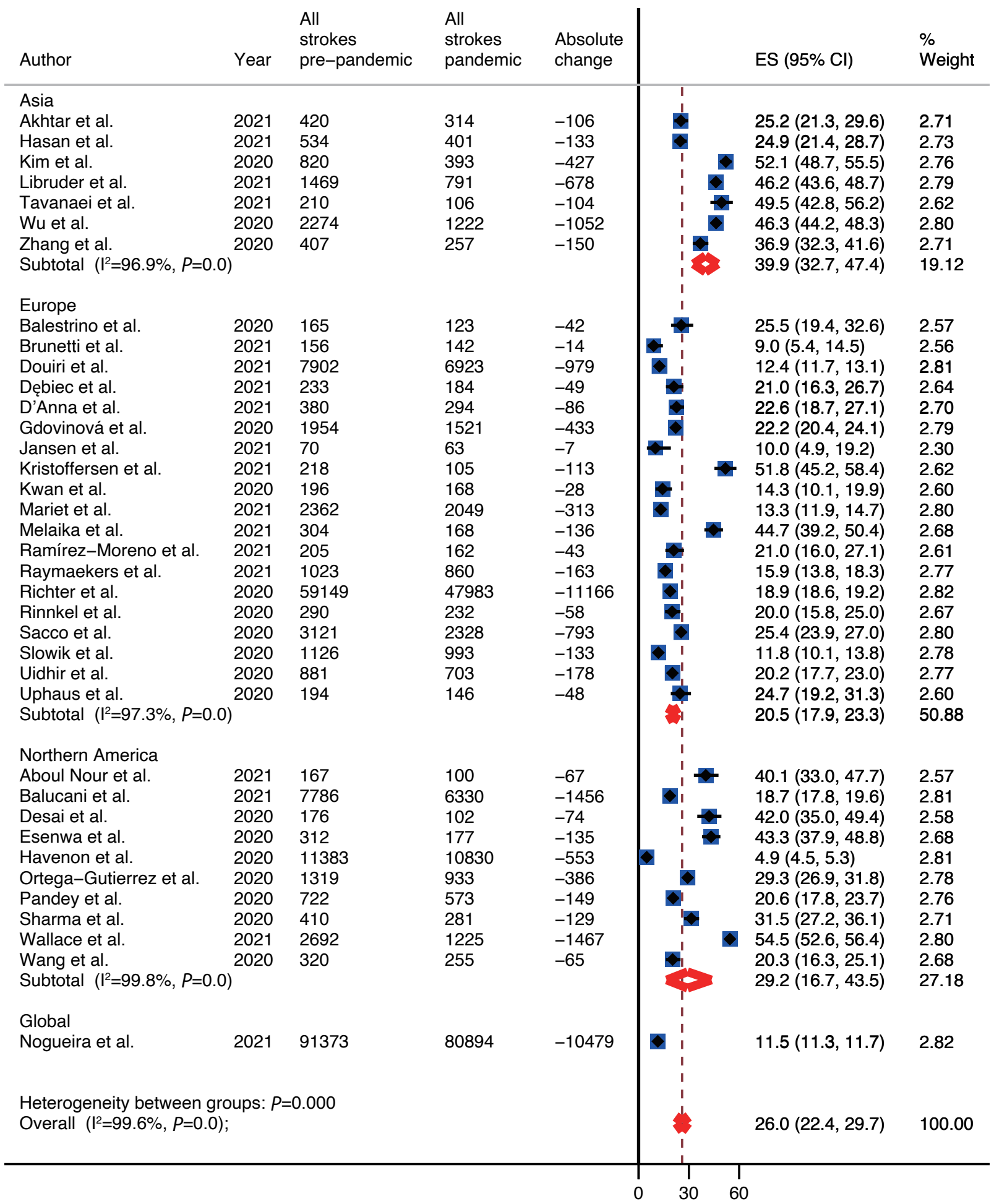

Figure 2. Percent change in all strokes by geographic region. $\mathrm{ES}$, effect size; $\mathrm{Cl}$, confidence interval.

\section{Regional difference}

Included studies reported on rates of stroke presentations from Asia, Europe, and North America. The highest decrease in presentations for all types of strokes combined as well as ischemic strokes, hemorrhagic strokes, and TIAs during the pandemic was reported from Asia, 39.9\% (95\% Cl, 32.7 to 47.4), 40.8\% (95\% Cl, 33.3 to 48.5$), 31.0 \%(95 \% \mathrm{Cl}, 11.2$ to 55.2$)$, and $51.5 \%(95 \% \mathrm{Cl}, 47.1$ to 56.0), respectively (Table 1 and Figure 2). Whereas Europe had the smallest decrease in rates of presentations for all types of strokes combined, ischemic strokes, 


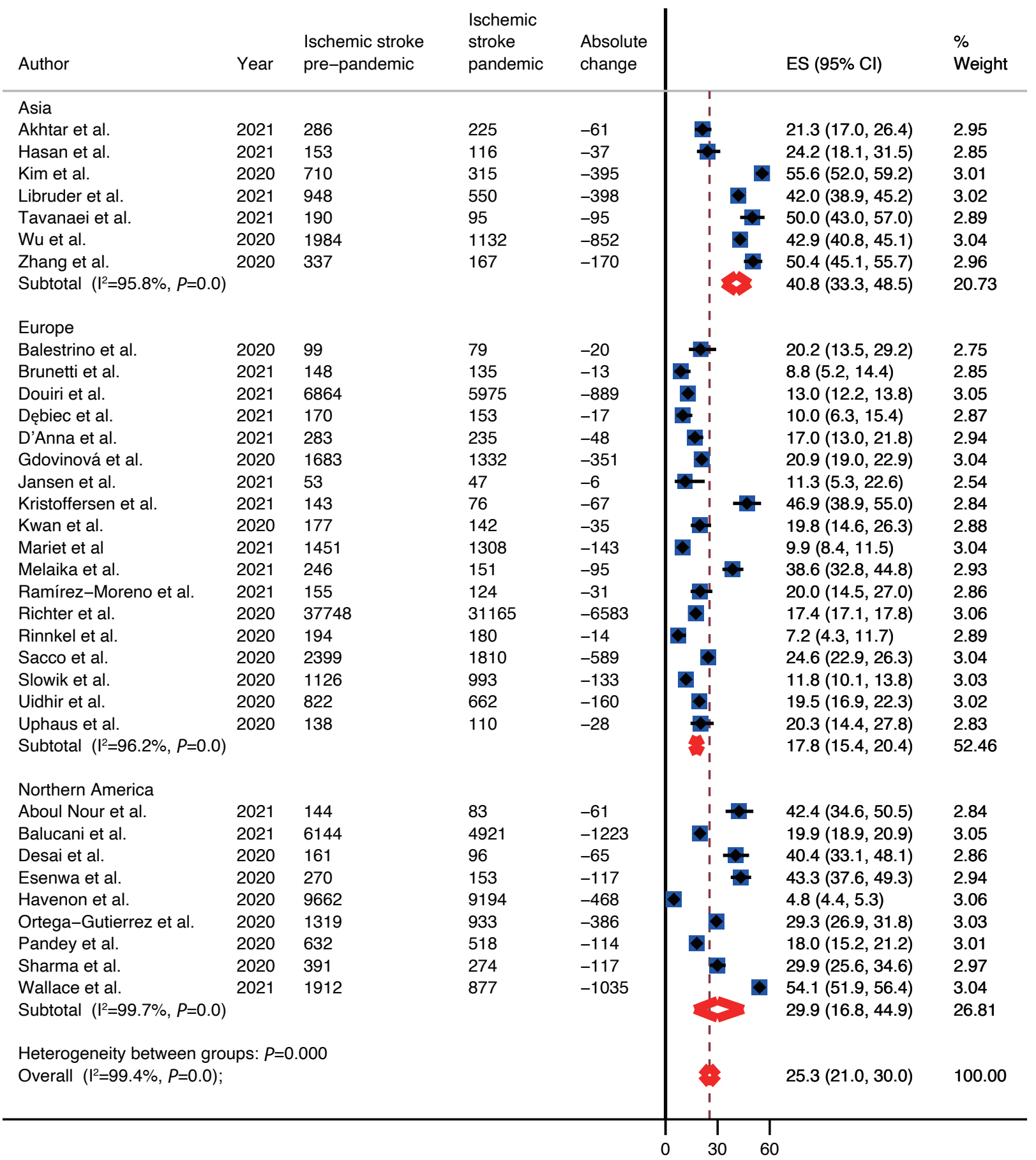

Figure 3. Percent change in the number of ischemic strokes. ES, effect size; $\mathrm{Cl}$, confidence interval.

hemorrhagic strokes, and TIAs, 20.5\% (95\% Cl, 17.9 to 23.3), $17.8 \%(95 \% \mathrm{Cl}, 15.4$ to 20.4$), 25.6 \%(95 \% \mathrm{Cl}, 18.8$ to 33.0$)$, and $38.3 \%(95 \% \mathrm{Cl}, 30.9$ to 45.9$)$ (Table 1 and Figure 2). Rates of presentations for all strokes combined, ischemic strokes, hemorrhagic strokes, and TIA decreased in North America by $29.2 \%(95 \% \mathrm{Cl}, 16.7$ to 43.5$), 29.9 \%(95 \% \mathrm{Cl}, 16.8$ to 44.9$)$, $25.8 \%(95 \% \mathrm{Cl}, 10.9$ to 44.1$)$, and $49.9 \%(95 \% \mathrm{Cl}, 17.5$ to 82.3) (Table 1 and Figure 2). Highest decrease in rates of stroke mimics was reported from North America 78.1\% (95\% Cl, 68.9 to 85.2$)$ in comparison to $52.8 \%(95 \% \mathrm{Cl}, 47.5$ to 58.1$)$ in Asia and $39.7 \%(95 \% \mathrm{Cl}, 29.2$ to 50.7$)$ in Europe (Table 1 and Figure 2).

The admission rates of all strokes were reported to have dropped maximally during the pandemic in regions of the world that were most severely affected by the pandemic like certain states of the USA (California, Texas, New York, Illinois, 


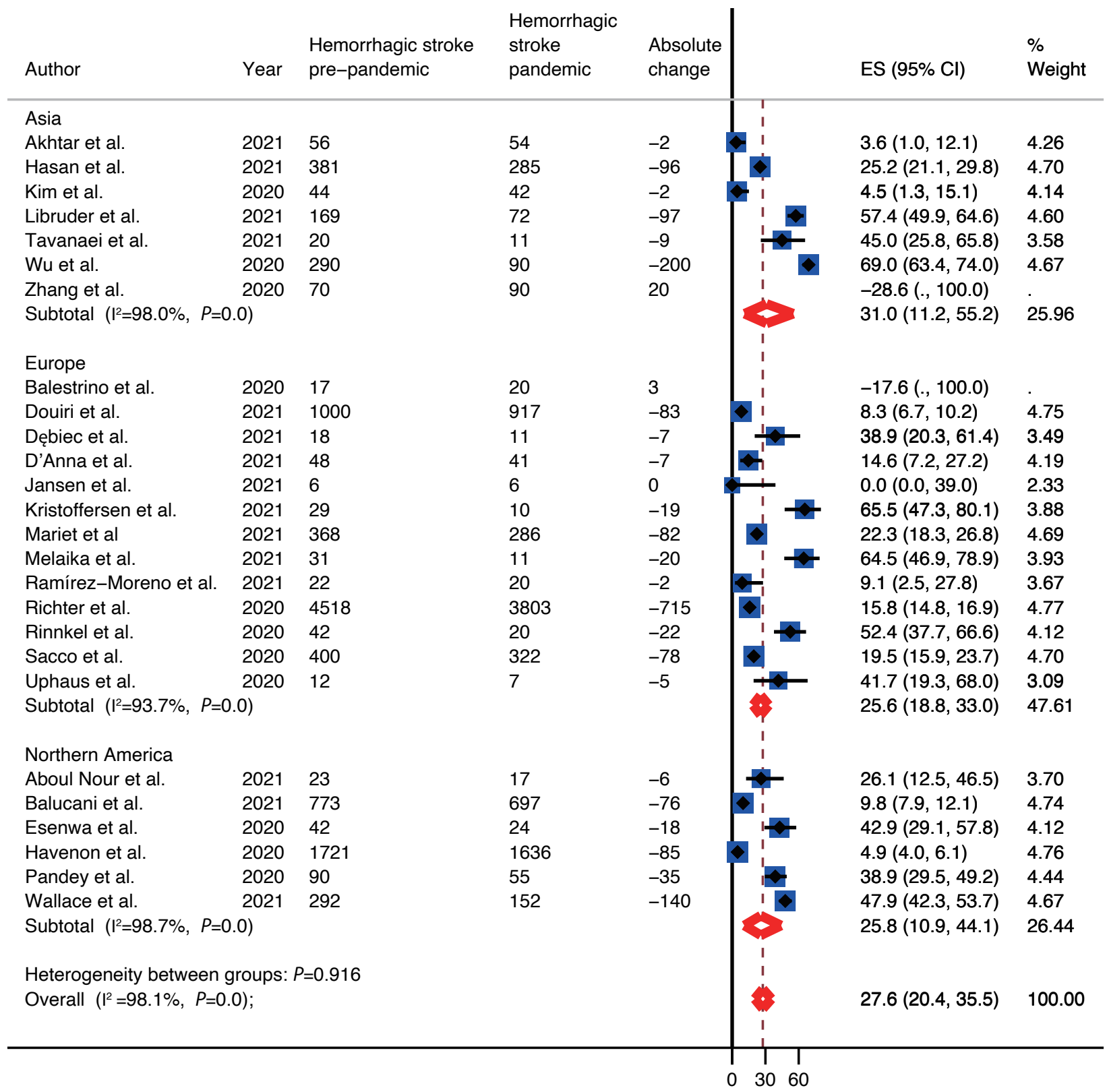

Figure 4. Percent change in the number of hemorrhagic strokes. $\mathrm{ES}$, effect size; $\mathrm{Cl}$, confidence interval.

Georgia, Ohio, Pennsylvania, New Jersey), ${ }^{31,32,41,46}$ Italy, $_{1}^{28,45} \operatorname{Iran}_{1}^{48}$ and Germany. ${ }^{50}$

\section{Time from onset to admission}

As stroke treatment is time-sensitive, we next analyzed the time (in minutes) from onset/last seen well to hospital arrival. The onset-to-door time was reported in 14/37 studies. ${ }^{29,30,44,46,48,49,52,54,55,57-59,61,63}$ There was no difference in mean onset-to-door time during pandemic when compared to pre-pandemic period (standardized mean difference $=-0.2$; $95 \% \mathrm{Cl}_{1}-0.8$ to 0.3$)$.

\section{Thrombolysis and endovascular treatment}

The effect of the pandemic on the rates of thrombolysis was reported in 28/37 studies and 25/37 studies reported on the rates of EVT before and during the pandemic. The rate of intravenous thrombolytic (IVT) therapy for acute ischemic strokes dropped by $27.2 \%$ during the pandemic $(95 \% \mathrm{Cl}, 22.7$ to 32.0$)$ (Supplementary Figure 10). This drop in rates of IVT was highest in Asia (40.3\%; 95\% Cl, 27.8 to 53.3) followed by North America (26.9\%; 95\% Cl, 12.7 to 43.9) and Europe (25.7\%; $95 \% \mathrm{Cl}, 19.7$ to 32.1 ) (Supplementary Figure 10). The likelihood of receiving IVT therapy did not differ between pre-pandemic and pandemic periods in primary stroke centers odds ratio (OR) 


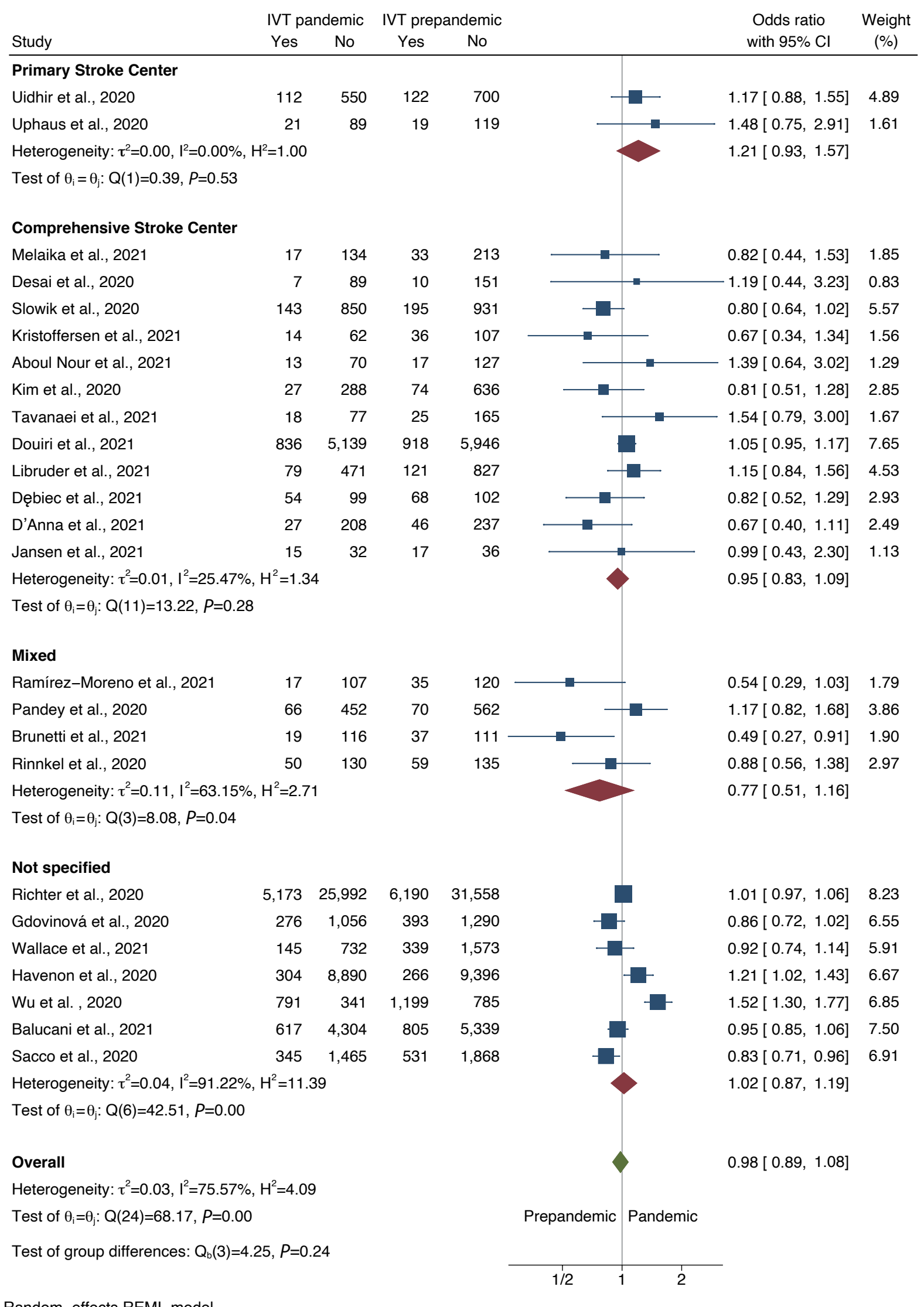

Figure 5. Probability of receiving intravenous thrombolytic (IVT) based on type of stroke center. Cl, confidence interval; REML, restricted maximum likelihood. 


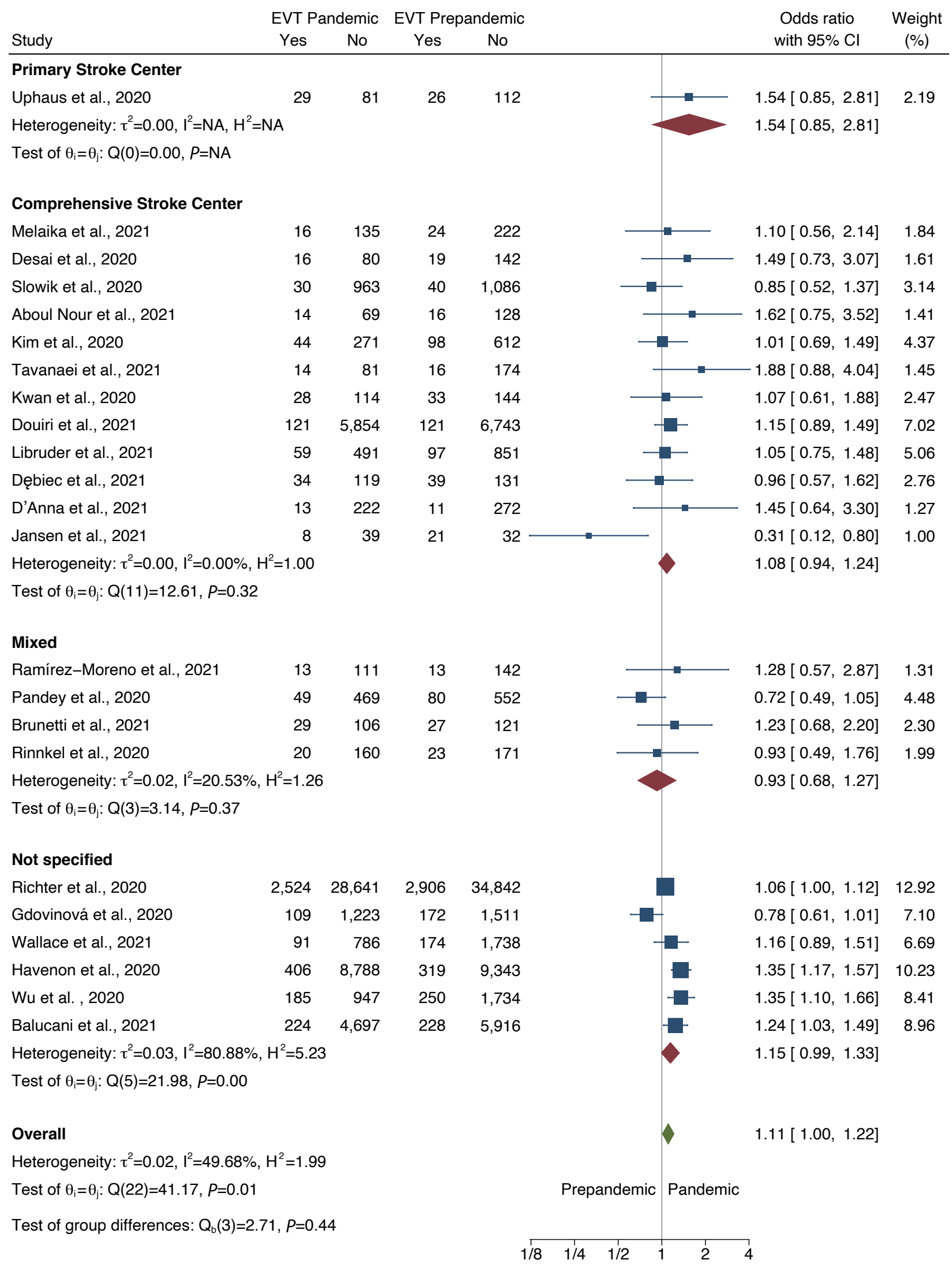

Random-effects REML model

Figure 6. Probability of being treated with endovascular thrombectomy (EVT) based on type of stroke center. $\mathrm{Cl}$, confidence interval; NA, not appplicable; REML, restricted maximum likelihood. 
$1.21(95 \% \mathrm{Cl}, 0.93$ to 1.57$)$ as well as in comprehensive stroke centers OR 0.95 ( $95 \% \mathrm{Cl}, 0.83$ to 1.09) (Figure 5). Although rates of EVT decreased during the pandemic by $20 \%\left(95 \% \mathrm{Cl}_{\text {, }}\right.$ 13.7 to 27.0) (Supplementary Figure 11), the likelihood of receiving EVT increased during the pandemic OR $1.11\left(95 \% \mathrm{Cl}_{\text {, }}\right.$ 1.00 to 1.22) (Figure 6). Largest decrease in rates of EVT was in Asia $34.2 \%(95 \% \mathrm{Cl}, 19.4$ to 50.7$)$ followed by North America $20.7 \%(95 \% \mathrm{Cl}, 6.8$ to 39.2$)$ and Europe $15.6 \%(95 \% \mathrm{Cl}, 9.0$ to 23.5). The likelihood of receiving EVT did not differ between two periods in comprehensive stroke center $\left(\mathrm{OR}, 1.08 ; 95 \% \mathrm{Cl}_{\text {, }}\right.$ 0.94 to 1.24$)$ as well as in primary stroke center $(O R, 1.54 ; 95 \%$ $\mathrm{Cl}, 0.85$ to 2.81) (Supplementary Figure 11).

\section{Discussion}

In this systematic review and meta-analysis of 37 fair-to-good quality studies reporting the rates of stroke presentations in relation to the COVID-19 pandemic, we found that there was an overall significant decrease ranging between 25\% and 50\% in all stroke types including ischemic, hemorrhagic, TIAs, and stroke mimics during the months of the COVID-19 pandemic when compared with the pre-pandemic period. Stroke presentations declined nearly by approximately $40 \%$ for patients with mild symptoms. Although the absolute rates of IVT and EVT decreased during the pandemic, the likelihood of being treated with reperfusion therapy did not change during the pandemic either in primary or in comprehensive stroke centers. This systematic review and meta-analysis included some observational studies with publication bias but it is because of observational nature of studies and unique period of pandemic that might have affected data collection.

Among stroke categories, patients presenting with TIA had the highest decline during pandemic, with a decrease of $40 \%$. Due to transient nature of neurological symptoms, patients may have chosen not to seek medical care as it might increase the risk of contracting COVID-19 infection. This trend is worrisome as it may lead to delay in diagnosis and initiation of prevention therapies. Patients with TIA are at higher risk of stroke in early period after TIA. ${ }^{14,21}$ There is considerable evidence that the risk of stroke is reduced significantly with appropriate assessment and early treatment. ${ }^{21}$ Whether delay in delivery of appropriate treatment will affect stroke outcomes subsequently is therefore a big concern. Population-based awareness campaigns to highlight the need to seek early medical attention should be conducted in the community, especially for those with TIAs and milder symptoms.

The rates of stroke mimics were significantly reduced by a percentage ranging from $33.5 \%$ to $58 \%$. In the study from Oa- tar, a striking decrease to nearly one-thirds in rates of stroke mimic admissions was the major reason for the fall in stroke admissions during the pandemic months compared with the preceding months. ${ }^{8}$ Patients with stroke mimics may avoid hospitalization due to fear of contracting COVID-19 infection. $13,15,16,28$

Similar to TIAs, mild strokes decreased by $40 \%$ during the pandemic. In comparison, moderate strokes decreased by $25 \%$ and severe strokes decreased by $29 \%$. Whereas, two recent systematic reviews and meta-analysis on stroke in patients with COVID-19 infections revealed that stroke is an uncommon complication of the illness and develops in less than 1.5\% of patients. ${ }^{64,65}$ Interestingly, initial reports also suggested that strokes of increased severity were seen more frequently in patients with severe COVID-19 infections admitted to hospitals. ${ }^{7}$ These cases may be secondary to the direct prothrombotic effects of the COVID-19 illness. There are reports of the formation of recurrent thrombi during the treatment of acute stroke. ${ }^{7}$ The COVID-19 virus may directly damage the cerebral vascular endothelium, making it more prothrombotic and this may explain the higher incidence of severe strokes. ${ }^{8,9,66-69}$

While different trends were observed for thrombolysis delivery in various studies across the globe, our composite analysis shows that the rates of both IVT and EVT dropped by slightly more than one-fourth and one-fifth during the pandemic. This may be related to possible delayed hospital arrival and an overall decrease in the absolute number of patients with mild and moderate stroke seeking medical care. ${ }^{21,29,30,46,54,55,59,60,62,70}$ However, the likelihood of being treated with IVT did not differ between two periods in comprehensive stroke centers and that of being treated with EVT increased during the pandemic, which might be due to adequate changes made in workflow of acute stroke care in comprehensive stroke centers. ${ }^{71}$ Higher likelihood of being treated with EVT might also have been caused by higher likelihood of large vessel occlusions due to prothrombotic state driven by COVID-19 virus, as reported by multiple studies. $^{7-9,66-69}$

There was a decrease in the rates for all types of stroke from all geographical regions of the world. These findings are similar to the decrease in admission rates of several other illnesses. ${ }^{4-6}$ A decrease in admission rates for ACS has been reported from all geographic regions of the world and appears to parallel the severity of the lockdowns. ${ }^{72} \mathrm{~A}$ decrease for most acute and chronic illnesses has also been reported from New York recently, where the effect was most apparent for infections and septicemia. ${ }^{73}$ In Qatar, a decline in admissions to the emergency department varying from 9\% to $75 \%$ was observed for acute surgical emergencies, ACS, bone fractures, and cancer whereas 
admissions for respiratory conditions increased. ${ }^{5}$ In Finland, there was a reduction in the rates of several acute medical illnesses seen in the emergency department, including infections (28\%), back or limb pain (31\%), and psychiatric illness (19\%). Interestingly and in contrast, there was no decrease in the number of stroke or ACS admissions during the period of observation. ${ }^{21}$ This may be driven by selection bias due to severity of stroke symptoms or reporting of acutely managed cases.

The most prevalent hypothesis for decline in rates of presentation of acute illnesses to the hospital relates to the fear of contracting COVID-19 when coming to the hospital. It may stand especially true for patients with transient or milder symptoms. ${ }^{20,21,40}$ This in turn may be magnified from 'stay-athome' orders, leading to deferring urgent care as suggested in a recent survey from the United Kingdom. ${ }^{74}$ In Germany, the initial early decline in stroke-related consultations in the pandemic and later increase for telemedicine services, paralleled the population activities during lockdowns. ${ }^{22}$ Another study from France also reported that there appeared to be a relationship between the decrease in stroke admissions and the severity of the COVID-19 pandemic. $^{60}$ The alternative hypothesis is that of decreased incidence of cardiovascular events related to lifestyle changes. ${ }^{40,75}$ Similarly, in Greece the significant decrease in ACS admissions in three municipalities appeared to be directly related to lifestyle changes including reduced passive smoking, working hours, alcohol and junk food consumption, and increased sleeping hours related to lockdown. ${ }^{76} \mathrm{Al}-$ though appealing, the study mainly addressed people with low burden of cardiovascular risk factors and thus the results should be interpreted carefully.

Other factors proposed to explain the decrease in emergency visits for acute illnesses include reduced social contact resulting in lowered "third-party" detection of unappreciated acute stroke symptoms. ${ }^{40}$ Another speculation is that of beneficial reduction in air pollution related to decreased carbon dioxide emissions and lower temperatures in relation to lockdowns during the peak of the pandemic. ${ }^{21,22,77}$ A decrease in physical activity during lockdown may also have potential protective effects. An increase in physical activity is known to increase blood pressure, potentially increasing the risk of stroke and ACS. $^{20,78}$

Our study has certain strengths and limitations. First, it is a composite analysis of studies comparing pre-pandemic to pandemic period and thus addresses the skepticism around the commonly raised concerns regarding stroke care. Second, we not only compared stroke presentations, but also analyzed the effect of stroke severity on relative differences in presentations. Third, the results are based on studies from multiple continents and diverse regions which is reflective of the global impact of the pandemic. The main limitation of this analysis is that this was based on observational studies. Also, although the likelihood of thrombolysis and thrombectomy seems unchanged, the effects the pandemic might have on stroke outcomes in terms of secondary prevention warrants further study. Comprehensive prospective registries recording the above stated parameter may help address these concerns as the pandemic evolves.

\section{Conclusions}

We meta-analyzed 37 studies that reported the rates of stroke presentation before and during the COVID-19 pandemic from various geographic regions. Rates of all stroke types declined significantly during the pandemic, but most profoundly for transient and milder symptoms, and stroke mimics. This resulted in lower rates of treatments with IVT as well as EVT. Whether delay in delivery of secondary prevention for those with mild symptoms would affect eventual stroke outcomes in the long run needs further study.

\section{Supplementary materials}

Supplementary materials related to this article can be found online at https://doi.org/10.5853/jos.2021.01571.

\section{Disclosure}

The authors have no financial conflicts of interest.

\section{References}

1. Zhu N, Zhang D, Wang W, Li X, Yang B, Song J, et al. A novel coronavirus from patients with pneumonia in China, 2019. $N$ Engl J Med 2020;382:727-733.

2. WHO Director-General's opening remarks at the media briefing on COVID19: 11 March 2020. WHO. https://www.who. int/director-general/speeches/detail/who-director-general-sopening-remarks-at-the-media-briefing-on-covid-19---11march-2020. 2020. Accessed October 30, 2021.

3. Mafham MM, Spata E, Goldacre R, Gair D, Curnow P, Bray M, et al. COVID-19 pandemic and admission rates for and management of acute coronary syndromes in England. Lancet 2020;396:381-389.

4. Schwarz V, Mahfoud F, Lauder L, Reith W, Behnke S, Smola S, et al. Decline of emergency admissions for cardiovascular and cerebrovascular events after the outbreak of COVID-19. 
Clin Res Cardiol 2020;109:1500-1506.

5. Butt AA, Kartha AB, Masoodi NA, Azad AM, Asaad NA, Alhomsi MU, et al. Hospital admission rates, length of stay, and in-hospital mortality for common acute care conditions in COVID-19 vs. pre-COVID-19 era. Public Health 2020;189:611.

6. Kuitunen I, Ponkilainen VT, Launonen AP, Reito A, Hevonkorpi TP, Paloneva J, et al. The effect of national lockdown due to COVID-19 on emergency department visits. Scand J Trauma Resusc Emerg Med 2020;28:114.

7. Oxley TJ, Mocco J, Majidi S, Kellner CP, Shoirah H, Singh IP, et al. Large-vessel stroke as a presenting feature of COVID-19 in the young. N Engl J Med 2020;382:e60.

8. Akhtar N, Al Jerdi S, Mahfoud Z, Imam Y, Kamran S, Saqqur $M$, et al. Impact of COVID-19 pandemic on stroke admissions in Qatar. BMJ Neurol Open 2021;3:e000084.

9. Mehrpour M, Shuaib A, Farahani M, Hatamabadi HR, Fatehi Z, Ghaffari M, et al. Coronavirus disease 2019 and stroke in Iran: a case series and effects on stroke admissions. Int J Stroke 2020 Jun 26 [Epub]. https://doi.org/10.1177/1747493020937397.

10. Aguiar de Sousa D, Sandset EC, Elkind MSV. The curious case of the missing strokes during the COVID-19 pandemic. Stroke 2020;51:1921-1923.

11. Padmanabhan $N$, Natarajan I, Gunston $R$, Raseta M, Roffe C. Impact of COVID-19 on stroke admissions, treatments, and outcomes at a comprehensive stroke centre in the United Kingdom. Neurol Sci 2021;42:15-20.

12. Uchino K, Kolikonda MK, Brown D, Kovi S, Collins D, Khawaja $Z$, et al. Decline in stroke presentations during COVID-19 surge. Stroke 2020;51:2544-2547.

13. Perry R, Banaras A, Werring DJ, Simister R. What has caused the fall in stroke admissions during the COVID-19 pandemic? J Neurol 2020;267:3457-3458.

14. Rudilosso S, Laredo C, Vera V, Vargas M, Renú A, Llull L, et al. Acute stroke care is at risk in the era of COVID-19: experience at a comprehensive stroke center in Barcelona. Stroke 2020;51:1991-1995.

15. D'Anna L, Sheikh A, Bathula R, Elmamoun S, Oppong A, Singh $R$, et al. Decreasing referrals to transient ischaemic attack clinics during the COVID-19 outbreak: results from a multicentre cross-sectional survey. BMJ Open 2020;10:e041514.

16. Butt JH, Fosbøl EL, Østergaard L, Yafasova A, Andersson C, Schou $M$, et al. Effect of COVID-19 on first-time acute stroke and transient ischemic attack admission rates and prognosis in Denmark: a nationwide cohort study. Circulation 2020; 142:1227-1229.

17. Kansagra AP, Goyal MS, Hamilton S, Albers GW. Collateral effect of COVID-19 on stroke evaluation in the United States.
N Engl J Med 2020;383:400-401.

18. Bres Bullrich $M$, Fridman $S$, Mandzia JL, Mai LM, Khaw $A$, Vargas Gonzalez JC, et al. COVID-19: stroke admissions, emergency department visits, and prevention clinic referrals. Can J Neurol Sci 2020;47:693-696.

19. Kim YD, Nam HS, Sohn SI, Park H, Hong JH, Kim GS, et al. Care process of recanalization therapy for acute stroke during the COVID-19 outbreak in South Korea. J Clin Neurol 2021;17:6369.

20. Pasarikovski CR, da Costa L. The impact of the COVID-19 pandemic on stroke volume. Can J Neurol Sci 2020;47:847848.

21. Diegoli $H$, Magalhães $P S$, Martins $\mathrm{SC}$, Moro $\mathrm{CH}$, França $\mathrm{PH}$, Safanelli J, et al. Decrease in hospital admissions for transient ischemic attack, mild, and moderate stroke during the COVID-19 era. Stroke 2020;51:2315-2321.

22. Schlachetzki F, Wilfling $S$, Hubert ND, Wagner $A$, Haberl RL, Linker RA, et al. Decline and recurrence of stroke consultations during the COVID-19 pandemic lockdown parallels population activity levels. Cerebrovasc Dis 2021;50:317-325.

23. Kato $A$, Minami $Y$, Katsura $A$, Muramatsu $Y$, Sato $T$, Kakizaki $\mathrm{R}$, et al. Physical exertion as a trigger of acute coronary syndrome caused by plaque erosion. J Thromb Thrombolysis 2020;49:377-385.

24. Grau $A J$, Urbanek $C$, Palm F. Common infections and the risk of stroke. Nat Rev Neurol 2010;6:681-694.

25. Page MJ, McKenzie JE, Bossuyt PM, Boutron I, Hoffmann TC, Mulrow CD, et al. The PRISMA 2020 statement: an updated guideline for reporting systematic reviews. BMJ 2021;372:n71.

26. Wells GA, Shea B, O'Connell D, Peterson J, Welch V, Losos M, et al. The Newcastle Ottawa Scale (NOS) for assessing the quality of non-randomised studies in meta-analyses. Ottawa Hospital Research Institute. http://www.ohri.ca/programs/ clinical_epidemiology/oxford.asp. 2021. Accessed October 30, 2021.

27. McGrath $S$, Zhao $X$, Steele $R$, Thombs BD, Benedetti A; DEPRESsion Screening Data (DEPRESSD) Collaboration. Estimating the sample mean and standard deviation from commonly reported quantiles in meta-analysis. Stat Methods Med Res 2020 Jan 30 [Epub]. https://doi.org/10.1177/0962280219889080.

28. Balestrino $M$, Coccia $A$, Boffa AS, Furgani A, Bermano F, Finoc-

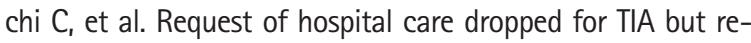
mained stable for stroke during COVID-19 pandemic at a large Italian university hospital. Intern Emerg Med 2021;16:735739.

29. Balucani C, Carhuapoma JR, Canner JK, Faigle $R$, Johnson $B$, Aycock $A$, et al. Exploring the collateral damage of the COVID-19 pandemic on stroke care: a statewide analysis. 
Stroke 2021;52:1822-1825.

30. Brunetti V, Broccolini A, Caliandro P, Di lorio R, Monforte M, Morosetti $R$, et al. Effect of the COVID-19 pandemic and the lockdown measures on the local stroke network. Neurol Sci 2021;42:1237-1245.

31. Desai SM, Guyette FX, Martin-Gill C, Jadhav AP. Collateral damage: impact of a pandemic on stroke emergency services. J Stroke Cerebrovasc Dis 2020;29:104988.

32. Esenwa C, Parides MK, Labovitz DL. The effect of COVID-19 on stroke hospitalizations in New York City. J Stroke Cerebrovasc Dis 2020;29:105114.

33. Gdovinová Z, Vitková M, Baráková A, Cvopová A. The impact of the COVID-19 outbreak on acute stroke care in Slovakia: data from across the country. Eur J Neurol 2021;28:3263-3266.

34. Hasan AT, Das SC, Islam MS, Mansur M, Shawon MS, Hassan $\mathrm{R}$, et al. Impact of COVID-19 on hospital admission of acute stroke patients in Bangladesh. PLoS One 2021;16:e0240385.

35. de Havenon A, Ney J, Callaghan B, Delic A, Hohmann S, Shippey $E_{\text {, et }}$ al. A rapid decrease in stroke, acute coronary syndrome, and corresponding interventions at 65 United States hospitals following emergence of COVID-19. medRxiv 2020 May 11. https://doi.org/10.1101/2020.05.07.20083386.

36. Kim TJ, Kim BJ, Gwak DS, Lee JS, Kim JY, Lee KJ, et al. Modification of acute stroke pathway in Korea after the coronavirus disease 2019 outbreak. Front Neurol 2020;11:597785.

37. Kristoffersen ES, Jahr SH, Thommessen B, Rønning OM. Effect of COVID-19 pandemic on stroke admission rates in a Norwegian population. Acta Neurol Scand 2020;142:632-636.

38. Kwan J, Brown M, Bentley P, Brown Z, D'Anna L, Hall C, et al. Impact of COVID-19 pandemic on a regional stroke thrombectomy service in the United Kingdom. Cerebrovasc Dis 2021;50:178-184.

39. Ramírez-Moreno JM, Portilla-Cuenca JC, Hariramani-Ramchandani R, Rebollo B, Bermejo Casado I, Macías-Sedas P, et al. Slump in hospital admissions for stroke, a fact of an uncertain nature that requires explanation. Brain Sci 2021;11:92.

40. Nogueira RG, Qureshi MM, Abdalkader M, Martins SO, Yamagami H, Qiu Z, et al. Global impact of COVID-19 on stroke care and IV thrombolysis. Neurology 2021;96:e2824-e2838.

41. Ortega-Gutierrez S, Farooqui M, Zha A, Czap A, Sebaugh J, Desai $S$, et al. Decline in mild stroke presentations and intravenous thrombolysis during the COVID-19 pandemic: the Society of Vascular and Interventional Neurology Multicenter Collaboration. Clin Neurol Neurosurg 2021;201:106436.

42. Pandey AS, Daou BJ, Tsai JP, Zaidi SF, Salahuddin H, Gemmete $\mathrm{J}$, et al. Letter: COVID-19 pandemic: the Bystander effect on stroke care in Michigan. Neurosurgery 2020;87:E397-E399.

43. Richter D, Eyding J, Weber R, Bartig D, Grau A, Hacke W, et al. Analysis of nationwide stroke patient care in times of COVID-19 pandemic in Germany. Stroke 2021;52:716-721.

44. Rinkel LA, Prick JC, Slot RE, Sombroek NM, Burggraaff J,

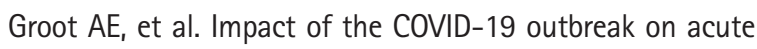
stroke care. J Neurol 2021;268:403-408.

45. Sacco S, Ricci S, Ornello R, Eusebi P, Petraglia L, Toni D, et al. Reduced admissions for cerebrovascular events during COVID-19 outbreak in Italy. Stroke 2020;51:3746-3750.

46. Sharma M, Lioutas VA, Madsen T, Clark J, O'Sullivan J, Elkind MS, et al. Decline in stroke alerts and hospitalisations during the COVID-19 pandemic. Stroke Vasc Neurol 2020;5:403405.

47. Słowik A, Nowak R, Popiela T. Significant fall in stroke admissions in the Malopolska Voivodeship of Poland during the COVID-19 pandemic. Neurol Neurochir Pol 2020;54:471-472.

48. Tavanaei R, Yazdani KO, Akhlaghpasand M, Zali A, OraeeYazdani S. Changed pattern of hospital admission in stroke during COVID-19 pandemic period in Iran: a retrospective study. Neurol Sci 2021;42:445-453.

49. Mag Uidhir F, Bathula R, Sivagnanaratnam A, Abdul-Saheb M, Devine J, Cohen DL. Impact of COVID-19 on stroke caseload in a major hyperacute stroke unit. J Stroke Cerebrovasc Dis 2020;29:105383.

50. Uphaus T, Gröschel S, Hayani E, Hahn M, Steffen F, Gröschel K. Stroke care within the COVID-19 pandemic-increasing awareness of transient and mild stroke symptoms needed. Front Neurol 2020;11:581394.

51. Wang J, Chaudhry SA, Tahsili-Fahadan P, Altaweel LR, Bashir S, Bahiru Z, et al. The impact of COVID-19 on acute ischemic stroke admissions: analysis from a community-based tertiary care center. J Stroke Cerebrovasc Dis 2020;29:105344.

52. Wu Y, Chen F, Wang Z, Feng W, Liu Y, Wang Y, et al. Reductions in hospital admissions and delays in acute stroke care during the pandemic of COVID-19. Front Neurol 2020;11:584734.

53. Zhang LL, Guo YJ, Lin YP, Hu RZ, Yu JP, Yang J, et al. Stroke care in the first affiliated hospital of Chengdu Medical College during the COVID-19 outbreak. Eur Neurol 2020;83:630635.

54. Aboul Nour H, Affan M, Mohamed G, Mohamud A, Schultz L, Latack K, et al. Impact of the COVID-19 pandemic on acute stroke care, time metrics, outcomes, and racial disparities in a Southeast Michigan Health System. J Stroke Cerebrovasc Dis 2021;30:105746.

55. D'Anna L, Brown M, Oishi S, Ellis N, Brown Z, Bentley P, et al. Impact of national lockdown on the hyperacute stroke care and rapid transient ischaemic attack outpatient service in a comprehensive tertiary stroke centre during the COVID-19 pandemic. Front Neurol 2021;12:627493. 
56. Dębiec A, Bilik M, Piasecki P, Stępień A, Staszewski J. Effect of COVID-19 pandemic on stroke admissions and quality of stroke interventional treatment in Masovian Voivodeship. Neurol Neurochir Pol 2021;55:223-226.

57. Douiri A, Muruet W, Bhalla A, James M, Paley $L$, Stanley $K_{1}$ et al. Stroke care in the United Kingdom during the COVID-19 pandemic. Stroke 2021;52:2125-2133.

58. Jansen R, Lee Jl, Turowski B, Kaschner M, Caspers J, Bernhard $M$, et al. Consequences of COVID-19 pandemic lockdown on emergency and stroke care in a German tertiary stroke center. Neurol Res Pract 2021;3:21.

59. Libruder C, Ram A, Hershkovitz Y, Tanne D, Bornstein NM, Leker RR, et al. Reduction in acute stroke admissions during the COVID-19 pandemic: data from a National Stroke Registry. Neuroepidemiology 2021;55:354-360.

60. Mariet AS, Giroud M, Benzenine E, Cottenet J, Roussot $A_{1}$ Aho-Glélé LS, et al. Hospitalizations for stroke in France during the COVID-19 pandemic before, during, and after the national lockdown. Stroke 2021;52:1362-1369.

61. Melaika K, Sveikata L, Wiśniewski $A$, Jaxybayeva A, Ekkert $A_{\text {, }}$ Jatužis $D$, et al. Changes in prehospital stroke care and stroke mimic patterns during the COVID-19 lockdown. Int J Environ Res Public Health 2021;18:2150.

62. Raymaekers V, Demeestere J, Bellante F, De Blauwe S, De Raedt S, Dusart A, et al. The impact of COVID-19 on acute stroke care in Belgium. Acta Neurol Belg 2021;121:1251-1258.

63. Wallace AN, Asif KS, Sahlein DH, Warach SJ, Malisch T, LaFranchise EF, et al. Patient characteristics and outcomes associated with decline in stroke volumes during the early COVID-19 pandemic. J Stroke Cerebrovasc Dis 2021;30:105569.

64. Katsanos AH, Palaiodimou L, Zand R, Yaghi S, Kamel H, Navi $\mathrm{BB}$, et al. The impact of SARS-CoV-2 on stroke epidemiology and care: a meta-analysis. Ann Neurol 2021;89:380-388.

65. Nannoni S, de Groot R, Bell S, Markus HS. Stroke in COVID-19: a systematic review and meta-analysis. Int J Stroke 2021;16: 137-149.

66. Clerkin KJ, Fried JA, Raikhelkar J, Sayer G, Griffin JM, Masoumi $A_{1}$ et al. COVID-19 and cardiovascular disease. Circulation 2020;141:1648-1655.

67. Lodigiani C, lapichino G, Carenzo L, Cecconi M, Ferrazzi P, Sebastian T, et al. Venous and arterial thromboembolic complications in COVID-19 patients admitted to an academic hospital in Milan, Italy. Thromb Res 2020;191:9-14.

68. Matschke J, Lütgehetmann M, Hagel C, Sperhake JP,

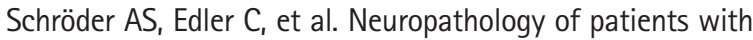

COVID-19 in Germany: a post-mortem case series. Lancet Neurol 2020;19:919-929.

69. Wichmann D, Sperhake JP, Lütgehetmann M, Steurer S, Edler $C$, Heinemann $A$, et al. Autopsy findings and venous thromboembolism in patients with COVID-19: a prospective cohort study. Ann Intern Med 2020;173:268-277.

70. Teo KC, Leung WC, Wong YK, Liu RK, Chan AH, Choi OM, et al. Delays in stroke onset to hospital arrival time during COVID-19. Stroke 2020;51:2228-2231.

71. Meyer D, Meyer BC, Rapp KS, Modir R, Agrawal K, Hailey L, et al. A stroke care model at an academic, comprehensive stroke center during the 2020 COVID-19 pandemic. J Stroke Cerebrovasc Dis 2020;29:104927.

72. Singh S, Fong HK, Desai R, Zwinderman AH. Impact of COVID-19 on acute coronary syndrome-related hospitalizations: a pooled analysis. Int J Cardiol Heart Vasc 2021;32:100718.

73. Blecker $S$, Jones $S A$, Petrilli CM, Admon AJ, Weerahandi $H$, Francois $F$, et al. Hospitalizations for chronic disease and acute conditions in the time of COVID-19. JAMA Intern Med 2021;181:269-271.

74. Blake I. Nearly half of heart patients find it harder to get medical treatment in lockdown. British Heart Foundation. https://www.bhf.org.uk/what-we-do/news-from-the-bhf/ news-archive/2020/june/half-heart-patients-harder-getmedical-treatment-lockdown. 2020. Accessed October 30, 2021.

75. Nguyen TN, Haussen DC, Qureshi MM, Yamagami H, Fujinaka T, Mansour OY, et al. Decline in subarachnoid haemorrhage volumes associated with the first wave of the COVID-19 pandemic. Stroke Vasc Neurol 2021 Mar 26 [Epub]. https:// doi.org/10.1136/svn-2020-000695.

76. Tsigkas G, Koufou EE, Katsanos K, Patrinos P, Moulias A, Miliordos I, et al. Potential relationship between lifestyle changes and incidence of hospital admissions for acute coronary syndrome during the COVID-19 lockdown. Front Cardiovasc Med 2021;8:604374.

77. Versaci F, Gaspardone A, Danesi A, Ferranti F, Mancone M, Mariano $E_{1}$ et al. Interplay between COVID-19, pollution, and weather features on changes in the incidence of acute coronary syndromes in early 2020. Int J Cardiol 2021;329:251-259.

78. Cian Z, Kang H, Tang K, Jiang C, Wu Z, Li Y, et al. Assessment of risk of aneurysmal rupture in patients with normotensives, controlled hypertension, and uncontrolled hypertension. J Stroke Cerebrovasc Dis 2016;25:1746-1752. 
Supplementary Table 1. Search strategy

\begin{tabular}{|c|c|c|}
\hline Search number & Search description & No. of results \\
\hline \multicolumn{3}{|c|}{ Full literature search on PubMed for COVID-19 and stroke } \\
\hline 1 & Stroke OR cerebrovascular accident & 378,999 \\
\hline 2 & COVID-19 OR Coronavirus Diseases 2019 & 160,172 \\
\hline 3 & Covid-19 OR Coronavirus Disease 2019 AND Stroke OR Cerebrovascular accident & 2,179 \\
\hline \multicolumn{3}{|c|}{ Full literature search on EMBASE for COVID-19 and stroke } \\
\hline 1 & Stroke.mp & 543,619 \\
\hline 2 & Limit 1 to $y r=" 2020-2021 "$ & 57,592 \\
\hline 3 & Covid-19.mp. & 157,189 \\
\hline 4 & Limit 3 to (human and English language and yr="2020 - 2021") & 143,572 \\
\hline 5 & 2 and 4 & 2,674 \\
\hline
\end{tabular}

COVID-19, coronavirus disease 2019. 
Supplementary Table 2. Characteristics of the included studies

\begin{tabular}{|c|c|c|c|c|c|c|c|c|c|c|c|c|c|c|c|}
\hline Author & Year & Location & Period ${ }^{*}$ PreP & Period $\mathrm{P}$ & Male PreP & Male P & RoB NOS & IS PreP & IS P & HS PreP & HSP & TIA PreP & TIAP & SM PreP & SM P \\
\hline Akhtar et al. ${ }^{8}$ & 2021 & Qatar & $\begin{array}{r}\text { Sep 2019- } \\
\text { Feb } 2020\end{array}$ & Mar-May 2020 & $73.4 \%$ & $73.3 \%$ & $\mathrm{G}$ & 286 & 225 & 56 & 54 & 78 & 35 & 262 & 102 \\
\hline Balestrino et al. ${ }^{28}$ & 2020 & Italy & $\begin{array}{l}\text { Mar 8-May 2, } \\
2019\end{array}$ & $\begin{array}{l}\text { Mar 8-May 2, } \\
2020\end{array}$ & NA & NA & $\mathrm{G}$ & 99 & 79 & 17 & 20 & 49 & 24 & NA & NA \\
\hline Balucani et al. $^{29}$ & 2021 & USA & $\begin{array}{l}\text { Mar 1-Sep 30, } \\
2019\end{array}$ & $\begin{array}{l}\text { Mar 1-Sep 30, } \\
2020\end{array}$ & NA & NA & G & 6,144 & 4,921 & 773 & 697 & 869 & 712 & NA & NA \\
\hline Brunetti et al. $^{30}$ & 2021 & Italy & $\begin{array}{l}\text { Mar 11-May 4, } \\
2019\end{array}$ & $\begin{array}{l}\text { Mar 11-May 4, } \\
2020\end{array}$ & $47.4 \%$ & $51.4 \%$ & G & 148 & 135 & NA & NA & 8 & 7 & NA & NA \\
\hline Desai et al. ${ }^{31}$ & 2020 & USA & $\begin{array}{l}\text { Mar } \\
\text { 2017/2018/2019 }\end{array}$ & Mar 2020 & NA & NA & G & 161 & 96 & & & 15 & 6 & NA & NA \\
\hline Esenwa et al. ${ }^{32}$ & 2020 & USA & $\begin{array}{l}\text { Jan 1-Feb 25, } \\
2020\end{array}$ & $\begin{array}{l}\text { Feb 26-Apr 18, } \\
2020\end{array}$ & $48 \%$ & $53 \%$ & $\mathrm{~F}$ & 270 & 153 & 42 & 24 & NA & NA & NA & NA \\
\hline Gdovinová et al. ${ }^{33}$ & 2020 & Slovakia & Jan and Feb, 2020 & Mar-Apr, 2020 & NA & NA & G & 1,683 & 1,332 & NA & NA & 271 & 189 & NA & NA \\
\hline Hasan et al. ${ }^{34}$ & 2021 & Bangladesh & $\begin{array}{l}\text { Jan 1-Mar 25, } \\
2020\end{array}$ & $\begin{array}{l}\text { Mar 26-Jun 30, } \\
2020\end{array}$ & NA & NA & $\mathrm{F}$ & 153 & 116 & 381 & 285 & NA & NA & NA & NA \\
\hline $\begin{array}{l}\text { de Havenon } \\
\text { et al. }^{35}\end{array}$ & 2020 & USA & $\begin{array}{l}\text { Feb-Mar } 2018 \\
\text { and } 2019\end{array}$ & Feb-Mar 2020 & NA & NA & $\mathrm{F}$ & 9,662 & 9,194 & 1,721 & 1,636 & NA & NA & NA & NA \\
\hline Kim et al. ${ }^{36}$ & 2020 & South Korea & $\begin{array}{l}\text { Sep 2019- Feb 17, } \\
2020\end{array}$ & $\begin{array}{l}\text { Feb 2020-May } \\
2020\end{array}$ & $59.3 \%$ & $60.8 \%$ & $\mathrm{~F}$ & 710 & 315 & 44 & 42 & 65 & 36 & NA & NA \\
\hline $\begin{array}{l}\text { Kristoffersen } \\
\text { et al. }\end{array}$ & 2021 & Norway & $\begin{array}{l}\text { Jan 3-Mar 12, } \\
2020\end{array}$ & $\begin{array}{l}\text { Mar 13-Apr 30, } \\
2020\end{array}$ & $55 \%$ & $51 \%$ & $\mathrm{~F}$ & 143 & 76 & 29 & 10 & 46 & 19 & NA & NA \\
\hline Kwan et al. ${ }^{38}$ & 2020 & UK & $\begin{array}{l}\text { Jan 1-Mar 2, } \\
2020\end{array}$ & $\begin{array}{l}\text { Mar 3-Apr 30, } \\
2020\end{array}$ & $58 \%$ & $64 \%$ & $\mathrm{~F}$ & 177 & 142 & NA & NA & NA & NA & NA & NA \\
\hline Nogueira et al. ${ }^{40}$ & 2021 & Global & $\begin{array}{l}\text { Nov, 2019-Feb, } \\
2020\end{array}$ & Mar-June 2020 & NA & NA & G & NA & NA & NA & NA & NA & NA & NA & NA \\
\hline $\begin{array}{l}\text { Ortega-Gutierrez } \\
\text { et al. }{ }^{41}\end{array}$ & 2020 & USA & $\begin{array}{l}\text { Mar 1-May 31, } \\
2019\end{array}$ & $\begin{array}{l}\text { Mar 1-May 31, } \\
2020\end{array}$ & $53.5 \%$ & $53 \%$ & G & 1,319 & 933 & NA & NA & NA & NA & NA & NA \\
\hline Pandey et al. ${ }^{42}$ & 2020 & USA & Mar 2019 & Mar 2020 & NA & NA & $\mathrm{F}$ & 632 & 518 & 90 & 55 & NA & NA & NA & NA \\
\hline $\begin{array}{l}\text { Ramírez-Moreno } \\
\text { et al. }\end{array}$ & 2021 & Spain & $\begin{array}{l}\text { Mar 15-May 10, } \\
2019\end{array}$ & $\begin{array}{c}\text { Mar 15-May } \\
10,2020\end{array}$ & $45 \%$ & $52 \%$ & G & 155 & 124 & 22 & 20 & 28 & 18 & NA & NA \\
\hline Richter et al. ${ }^{43}$ & 2020 & Germany & $\begin{array}{l}\text { Jan 16-Mar 15, } \\
2020\end{array}$ & $\begin{array}{c}\text { Mar 16-May } \\
15,2020\end{array}$ & $51.7 \%$ & $51.8 \%$ & $\mathrm{~F}$ & 37,748 & 31,165 & 4,518 & 3,803 & 16,883 & 1,3015 & NA & NA \\
\hline Rinkel et al. ${ }^{44}$ & 2020 & Netherlands & $\begin{array}{l}\text { Oct 21-Dec 8, } \\
2019\end{array}$ & $\begin{array}{l}\text { Mar 16-May 3, } \\
2020\end{array}$ & $47 \%$ & $59 \%$ & $\mathrm{~F}$ & 194 & 180 & 42 & 20 & 54 & 32 & 115 & 77 \\
\hline Sacco et al. ${ }^{45}$ & 2020 & Italy & Mar 2019 & Mar 2020 & $53.4 \%$ & $53 \%$ & G & 2,399 & 1,810 & 400 & 322 & 322 & 196 & 531 & 345 \\
\hline Sharma et al. ${ }^{46}$ & 2020 & USA & $\begin{array}{r}\text { Dec 31, 2018- } \\
\text { Apr 19, } 2019\end{array}$ & $\begin{array}{r}\text { Dec 31, 2019- } \\
\text { Apr 19, } 2020\end{array}$ & NA & NA & G & 391 & 274 & NA & NA & 19 & 7 & NA & NA \\
\hline Słowik et al. ${ }^{47}$ & 2020 & Poland & $\begin{array}{l}\text { Jan 1-Mar 4, } \\
2020\end{array}$ & $\begin{array}{l}\text { Mar 4-May 31, } \\
2020\end{array}$ & NA & NA & $\mathrm{F}$ & 1,126 & 993 & NA & NA & NA & NA & NA & NA \\
\hline Tavanaei et al. ${ }^{48}$ & 2021 & Iran & $\begin{array}{l}\text { Mar } 12019-J u n \\
12019\end{array}$ & $\begin{array}{l}\text { Mar } 12020- \\
\text { Jun } 12020\end{array}$ & $58.4 \%$ & $52.6 \%$ & G & 190 & 95 & 20 & 11 & NA & NA & NA & NA \\
\hline $\begin{array}{l}\text { Mag Uidhir } \\
\text { et al. }^{49}\end{array}$ & 2020 & $\begin{array}{l}\text { United } \\
\text { Kingdom }\end{array}$ & Jan-Jun 2019 & Jan-Jun 2020 & NA & NA & G & 822 & 662 & NA & NA & 59 & 41 & 275 & 206 \\
\hline Uphaus et al. ${ }^{50}$ & 2020 & Germany & $\begin{array}{l}\text { Jan } 1 \text { 2019-Feb } \\
2020\end{array}$ & Mar-Apr 2020 & $54.3 \%$ & $46.6 \%$ & G & 138 & 110 & 12 & 7 & 44 & 29 & NA & NA \\
\hline Wang et al. ${ }^{51}$ & 2020 & USA & $\begin{array}{l}\text { Dec 1. 2019-Mar } \\
\text { 11, } 2020\end{array}$ & $\begin{array}{c}\text { Mar 12, 2020- } \\
\text { Jun } 30,2020\end{array}$ & $51.9 \%$ & $53.3 \%$ & $\mathrm{~F}$ & NA & NA & NA & NA & NA & NA & NA & NA \\
\hline Wu et al. ${ }^{52}$ & 2020 & China & $\begin{array}{l}\text { Jan 24-Apr 29, } \\
2019\end{array}$ & $\begin{array}{l}\text { Jan 24-Apr 29, } \\
2020\end{array}$ & $67.2 \%$ & $66.7 \%$ & G & 1,984 & 1,132 & 290 & 90 & NA & NA & 80 & 59 \\
\hline Zhang et al. ${ }^{53}$ & 2020 & China & $\begin{array}{l}\text { Nov 2019-Mar } \\
2020\end{array}$ & $\begin{array}{l}\text { Apr 2020-Jul } \\
2020\end{array}$ & NA & NA & $\mathrm{F}$ & 337 & 167 & 70 & 90 & NA & NA & NA & NA \\
\hline $\begin{array}{l}\text { Aboul Nour } \\
\text { et al. }^{54}\end{array}$ & 2021 & USA & $\begin{array}{l}\text { Mar 20-May 20, } \\
2019\end{array}$ & $\begin{array}{l}\text { Mar 20-May } \\
20,2020\end{array}$ & $51 \%$ & $55 \%$ & G & 144 & 83 & 23 & 17 & NA & NA & 96 & 21 \\
\hline D'Anna et al. ${ }^{55}$ & 2021 & $\begin{array}{l}\text { United } \\
\text { Kingdom }\end{array}$ & $\begin{array}{l}\text { Mar 23-June 30, } \\
2019\end{array}$ & $\begin{array}{l}\text { Mar 23-June } \\
\text { 30, } 2020\end{array}$ & $48.8 \%$ & $56 \%$ & $\mathrm{~F}$ & 283 & 235 & 48 & 41 & 49 & 18 & 132 & 55 \\
\hline Dębiec et al. ${ }^{56}$ & 2021 & Poland & $\begin{array}{l}\text { Mar 1-Apr 30, } \\
2019\end{array}$ & $\begin{array}{l}\text { Mar 1-Apr 30, } \\
2020\end{array}$ & $46 \%$ & $53 \%$ & $\mathrm{~F}$ & 170 & 153 & 18 & 11 & 45 & 20 & NA & NA \\
\hline Douiri et al. ${ }^{57}$ & 2021 & $\begin{array}{l}\text { United } \\
\text { Kingdom }\end{array}$ & $\begin{array}{l}\text { Mar 23-Apr 30, } \\
2019\end{array}$ & $\begin{array}{l}\text { Mar 23-Apr 30, } \\
2020\end{array}$ & $51.6 \%$ & $52 \%$ & G & 6,864 & 5,975 & 1,000 & 917 & NA & NA & NA & NA \\
\hline Jansen et al. ${ }^{58}$ & 2021 & Germany & $\begin{array}{l}\text { Mar 16-Apr } 12 \\
2019\end{array}$ & $\begin{array}{l}\text { Mar 16-Apr } 12 \\
2020\end{array}$ & $45.7 \%$ & $47.6 \%$ & $\mathrm{~F}$ & 53 & 47 & 6 & 6 & 11 & 10 & NA & NA \\
\hline Libruder et al. ${ }^{59}$ & 2021 & Israel & $\begin{array}{l}\text { Jan 1-Mar 7, } \\
2020\end{array}$ & $\begin{array}{l}\text { Mar 8-Apr 30, } \\
2020\end{array}$ & $54.9 \%$ & $56.2 \%$ & G & 948 & 550 & 169 & 72 & 352 & 169 & NA & NA \\
\hline Mariet et al. ${ }^{60}$ & 2021 & France & Apr, 2019 & Apr, 2020 & NA & NA & G & 1,451 & 1,308 & 368 & 286 & 543 & 455 & NA & NA \\
\hline Melaika et al. ${ }^{61}$ & 2021 & Lithuania & $\begin{array}{l}\text { Dec 1, 2019- } \\
\text { Mar 15, } 2020\end{array}$ & $\begin{array}{c}\text { Mar 16-June } \\
16,2020\end{array}$ & $40.1 \%$ & $39.8 \%$ & $\mathrm{~F}$ & 246 & 151 & 31 & 11 & 27 & 6 & 164 & 83 \\
\hline $\begin{array}{l}\text { Raymaekers } \\
\text { et al. }{ }^{62}\end{array}$ & 2021 & Belgium & $\begin{array}{l}\text { Dec, } 2019 \text { till Feb, } \\
2020\end{array}$ & Mar-May 2020 & NA & NA & $\mathrm{F}$ & NA & NA & NA & NA & NA & NA & NA & NA \\
\hline Wallace et al. ${ }^{63}$ & 2021 & USA & $\begin{array}{l}\text { Jan 1-Feb 29, } \\
2020\end{array}$ & $\begin{array}{l}\text { Mar 20-Apr 25, } \\
2020\end{array}$ & $48.9 \%$ & $48 \%$ & G & 1,912 & 877 & 292 & 152 & 239 & 85 & NA & NA \\
\hline
\end{tabular}

PreP, pre-pandemic; P, pandemic; RoB, risk of bias; NOS, Newcastle-Ottawa Quality Assessment Scale; IS, ischemic stroke; HS, hemorrhagic stroke; TIA, transient ischemic attack; SM, stroke mimics; G, good; NA, not available; F, fair.

*Months are provided in their 3-letter abbreviated form. 
Supplementary Table 3. Characteristics of included studies based on stroke severity, IVT, and EVT

\begin{tabular}{|c|c|c|c|c|c|c|c|c|c|c|c|c|c|c|c|}
\hline Author & Year & $\begin{array}{l}\text { All } \\
\text { strokes } \\
\text { PreP }\end{array}$ & $\begin{array}{c}\text { All } \\
\text { strokes } \\
\text { P }\end{array}$ & $\begin{array}{l}\text { NIHSS } \\
<5 \\
\text { PreP }\end{array}$ & $\begin{array}{l}\text { NIHSS } \\
<5 \\
P\end{array}$ & $\begin{array}{l}\text { NIHSS } \\
5-15 \\
\text { PreP }\end{array}$ & $\begin{array}{c}\text { NIHSS } \\
5-15 \\
P\end{array}$ & $\begin{array}{l}\text { NIHSS } \\
>15 \\
\text { PreP }\end{array}$ & $\begin{array}{l}\text { NIHSS } \\
>15 \\
P\end{array}$ & $\begin{array}{l}\text { IVT } \\
\text { PreP }\end{array}$ & $\begin{array}{l}\text { IVT } \\
\mathrm{P}\end{array}$ & $\begin{array}{l}\text { EVT } \\
\text { PreP }\end{array}$ & $\begin{array}{c}\mathrm{EVT} \\
\mathrm{P}\end{array}$ & $\begin{array}{l}\text { NIHSS PreP } \\
\text { (mean } \pm \text { SD or } \\
\text { median [IOR]) }\end{array}$ & $\begin{array}{c}\text { NIHSS P } \\
\text { (mean } \pm \text { SD or } \\
\text { median }[I Q R])\end{array}$ \\
\hline Akhtar et al. ${ }^{8}$ & 2021 & 682 & 416 & 531 & 273 & 75 & 71 & 75 & 71 & NA & NA & NA & NA & NA & NA \\
\hline Balestrino et al. ${ }^{28}$ & 2020 & 165 & 123 & NA & NA & NA & NA & NA & NA & 195 & 143 & NA & NA & NA & NA \\
\hline Balucani et al. ${ }^{29}$ & 2021 & 7,786 & 6,330 & NA & NA & NA & NA & NA & NA & 805 & 617 & 228 & 224 & NA & NA \\
\hline Brunetti et al. $^{30}$ & 2021 & 156 & 142 & NA & NA & NA & NA & NA & NA & NA & NA & 5,191 & 4,533 & NA & NA \\
\hline Desai et al. ${ }^{31}$ & 2020 & 176 & 102 & 636 & 412 & 210 & 139 & 275 & 233 & NA & NA & NA & NA & NA & NA \\
\hline Esenwa et al. $^{32}$ & 2020 & 312 & 177 & 98 & 24 & 77 & 49 & 14 & 20 & 25 & 18 & 16 & 14 & NA & NA \\
\hline Gdovinová et al. ${ }^{33}$ & 2020 & 1,954 & 1,521 & NA & NA & NA & NA & NA & NA & 393 & 276 & 172 & 109 & $14.5 \pm 9$ & $16.9 \pm 13.9$ \\
\hline Hasan et al. ${ }^{34}$ & 2021 & 534 & 401 & NA & NA & NA & NA & NA & NA & NA & NA & NA & NA & NA & NA \\
\hline de Havenon et al. ${ }^{35}$ & 2020 & 11,383 & 10,830 & NA & NA & NA & NA & NA & NA & 266 & 304 & 319 & 406 & NA & NA \\
\hline Kim et al. ${ }^{36}$ & 2020 & 820 & 393 & 570 & 256 & 112 & 59 & 138 & 78 & NA & NA & NA & NA & $6.1 \pm 6.2$ & $6.6 \pm 6$ \\
\hline Kristoffersen et al. ${ }^{37}$ & 2021 & 218 & 105 & NA & NA & NA & NA & NA & NA & 35 & 17 & 13 & 13 & $4.2 \pm 6.1$ & $5.9 \pm 8.6$ \\
\hline Kwan et al. ${ }^{38}$ & 2020 & 196 & 168 & NA & $\mathrm{NA}$ & NA & NA & NA & NA & & & 19 & 16 & NA & NA \\
\hline Nogueira et al. ${ }^{40}$ & 2021 & 91,373 & 80,894 & NA & NA & NA & NA & NA & NA & 13,334 & 11,570 & NA & NA & NA & NA \\
\hline $\begin{array}{l}\text { Ortega-Gutierrez } \\
\text { et al. }^{41}\end{array}$ & 2020 & 1,319 & 933 & NA & NA & NA & NA & NA & NA & NA & NA & NA & NA & $10.4 \pm 12.5$ & $11.3 \pm 12.2$ \\
\hline Pandey et al. ${ }^{42}$ & 2020 & 722 & 573 & NA & NA & NA & NA & NA & NA & 70 & 66 & 80 & 49 & NA & NA \\
\hline $\begin{array}{l}\text { Ramírez-Moreno } \\
\text { et al. }^{39}\end{array}$ & 2021 & 205 & 162 & NA & NA & NA & NA & NA & NA & 19 & 21 & 26 & 29 & $6.4 \pm 1.4$ & $7.1 \pm 1.6$ \\
\hline Richter et al. ${ }^{43}$ & 2020 & 59,149 & 47,983 & NA & NA & NA & NA & NA & NA & 6,186 & 5,170 & 2,888 & 2,514 & NA & NA \\
\hline Rinkel et al. ${ }^{44}$ & 2020 & 405 & 309 & NA & NA & NA & NA & NA & NA & 59 & 50 & 23 & 20 & NA & NA \\
\hline Sacco et al. ${ }^{45}$ & 2020 & 3,652 & 2,673 & NA & NA & NA & NA & NA & NA & 531 & 345 & NA & NA & NA & NA \\
\hline Sharma et al. ${ }^{46}$ & 2020 & 410 & 281 & NA & NA & NA & NA & NA & NA & 20 & 30 & 43 & 49 & $8.2 \pm 2.5$ & $9.7 \pm 1$ \\
\hline Słowik et al. ${ }^{47}$ & 2020 & 1,126 & 993 & NA & NA & NA & NA & NA & NA & NA & NA & NA & NA & NA & NA \\
\hline Tavanaei et al. ${ }^{48}$ & 2021 & 210 & 106 & NA & NA & NA & NA & NA & NA & NA & NA & 33 & 28 & $5.1 \pm 4.3$ & $9.1 \pm 4.8$ \\
\hline Mag Uidhir et al. ${ }^{49}$ & 2020 & 1,156 & 909 & NA & NA & NA & NA & NA & NA & 122 & 112 & NA & NA & NA & NA \\
\hline Uphaus et al. $^{50}$ & 2020 & 194 & 146 & 89 & 85 & 25 & 27 & 33 & 24 & 37 & 19 & 27 & 29 & NA & NA \\
\hline Wang et al. ${ }^{51}$ & 2020 & 320 & 255 & NA & NA & NA & NA & NA & NA & 36 & 14 & NA & NA & $8.1 \pm 10.3$ & $6.3 \pm 5.4$ \\
\hline Wu et al. ${ }^{52}$ & 2020 & 2,354 & 1,281 & 1,075 & 468 & 886 & 501 & 324 & 192 & 1,199 & 791 & 250 & 185 & $8.4 \pm 7.8$ & $9.4 \pm 7.7$ \\
\hline Zhang et al. ${ }^{53}$ & 2020 & 407 & 257 & NA & NA & NA & NA & NA & NA & 36 & 17 & NA & NA & NA & NA \\
\hline Aboul Nour et al. ${ }^{54}$ & 2021 & 263 & 121 & NA & NA & NA & NA & NA & NA & 17 & 13 & 16 & 14 & $2(1-6)$ & $5(1-9)$ \\
\hline D'Anna et al. ${ }^{55}$ & 2021 & 512 & 349 & NA & NA & NA & NA & NA & NA & 46 & 27 & 11 & 13 & $4(0-29)$ & $7(0-30)$ \\
\hline Dębiec et al. ${ }^{56}$ & 2021 & 233 & 184 & NA & NA & NA & NA & NA & NA & 68 & 54 & 39 & 34 & $11.9 \pm 8$ & $10.2 \pm 7$ \\
\hline Douiri et al. ${ }^{57}$ & 2021 & 7,902 & 6,923 & 3,157 & 2,930 & 2,230 & 2,394 & 1,028 & 1,158 & 918 & 836 & 121 & 121 & $5(2-10)$ & $5(2-12)$ \\
\hline Jansen et al. ${ }^{58}$ & 2021 & 70 & 63 & NA & NA & NA & NA & NA & NA & 17 & 15 & 21 & 8 & $4(1-11)$ & $4(1.8-10)$ \\
\hline Libruder et al. ${ }^{59}$ & 2021 & 1,469 & 791 & 389 & 234 & 160 & 99 & 80 & 42 & 121 & 79 & 97 & 59 & $4.0(2-9)$ & $4.0(2-8)$ \\
\hline Mariet et al. ${ }^{60}$ & 2021 & 2,362 & 2,049 & NA & NA & NA & NA & NA & NA & NA & NA & NA & NA & NA & NA \\
\hline Melaika et al. ${ }^{61}$ & 2021 & 468 & 251 & NA & NA & NA & NA & NA & NA & 33 & 17 & 24 & 16 & $8(4-16)$ & $7(4-14)$ \\
\hline Raymaekers et al. ${ }^{62}$ & 2021 & 1,023 & 860 & NA & NA & NA & NA & NA & NA & 207 & 177 & 166 & 145 & NA & NA \\
\hline Wallace et al. ${ }^{63}$ & 2021 & 2,692 & 1,225 & 1,473 & 632 & NA & NA & 308 & 168 & 339 & 145 & 174 & 91 & $3(1-9)$ & $4(1-10)$ \\
\hline
\end{tabular}

PreP, pre-pandemic; P, pandemic; NIHSS, National Institutes of Health Stroke Scale; IVT, intravenous thrombolysis; EVT, endovascular thrombectomy; SD, standard deviation; IQR, interquartile range; NA, not available. 
Supplementary Table 4. MOOSE statement: reporting checklist for authors, editors, and reviewers of meta-analyses of observational studies

\begin{tabular}{|c|c|c|}
\hline Reporting criteria & Reported & Reported on page \\
\hline \multicolumn{3}{|l|}{ Reporting of background } \\
\hline Problem definition & Yes & 5 \\
\hline Hypothesis statement & Yes & 6 \\
\hline Description of study outcome(s) & Yes & 6 \\
\hline Type of exposure or intervention used & Yes & 6 \\
\hline Type of study design used & Yes & 6 \\
\hline Study population & Yes & 6 \\
\hline \multicolumn{3}{|l|}{ Reporting of search strategy } \\
\hline Qualifications of searchers (e.g., librarians and investigators) & Yes & 6 \\
\hline Search strategy, including time period included in the synthesis and keywords & Yes & 6 \\
\hline Effort to include all available studies, including contact with authors & No & \\
\hline Databases and registries searched & Yes & 6 \\
\hline Search software used, name and version, including special features used (e.g., explosion) & No & \\
\hline Use of hand searching (e.g., reference lists of obtained articles) & No & \\
\hline List of citations located and those excluded, including justification & Yes & 6 \\
\hline Method for addressing articles published in languages other than English & No & \\
\hline Method of handling abstracts and unpublished studies & No & \\
\hline Description of any contact with authors & No & \\
\hline \multicolumn{3}{|l|}{ Reporting of methods } \\
\hline Description of relevance or appropriateness of studies assembled for assessing the hypothesis to be tested & Yes & 7 \\
\hline Rationale for the selection and coding of data (e.g., sound clinical principles or convenience) & Yes & $6-7$ \\
\hline Documentation of how data were classified and coded (e.g., multiple raters, blinding, and interrater reliability) & Yes & 7 \\
\hline Assessment of confounding (e.g., comparability of cases and controls in studies where appropriate) & Yes & 7 \\
\hline $\begin{array}{l}\text { Assessment of study quality, including blinding of quality assessors; stratification or regression on possible } \\
\text { predictors of study results YES } 5\end{array}$ & Yes & 7 \\
\hline Assessment of heterogeneity & Yes & 8 \\
\hline $\begin{array}{l}\text { Description of statistical methods (e.g., complete description of fixed or random effects models, justification } \\
\text { of whether the chosen models account for predictors of study results, dose-response models, or cumulative } \\
\text { meta-analysis) in sufficient detail to be replicated }\end{array}$ & Yes & 8 \\
\hline Provision of appropriate tables and graphics & Yes & \\
\hline \multicolumn{3}{|l|}{ Reporting of results } \\
\hline Table giving descriptive information for each study included & Yes & Supplementary Table 2 \\
\hline Results of sensitivity testing (e.g., subgroup analysis) & Yes & Supplementary Figures 2-11 \\
\hline Indication of statistical uncertainty of findings & Yes & 8 \\
\hline \multicolumn{3}{|l|}{ Reporting of discussion } \\
\hline Quantitative assessment of bias (e.g., publication bias) & Yes & 11 \\
\hline Justification for exclusion (e.g., exclusion of non-English-language citations) & No & \\
\hline Assessment of quality of included studies & Yes & 11 \\
\hline \multicolumn{3}{|l|}{ Reporting of conclusions } \\
\hline Consideration of alternative explanations for observed results & No & \\
\hline $\begin{array}{l}\text { Generalization of the conclusions (i.e., appropriate for the data presented and within the domain of the } \\
\text { literature review) }\end{array}$ & Yes & 15 \\
\hline Guidelines for future research & No & \\
\hline Disclosure of funding source & Yes & 15 \\
\hline
\end{tabular}

MOOSE, Meta-analysis Of Observational Studies in Epidemiology. 


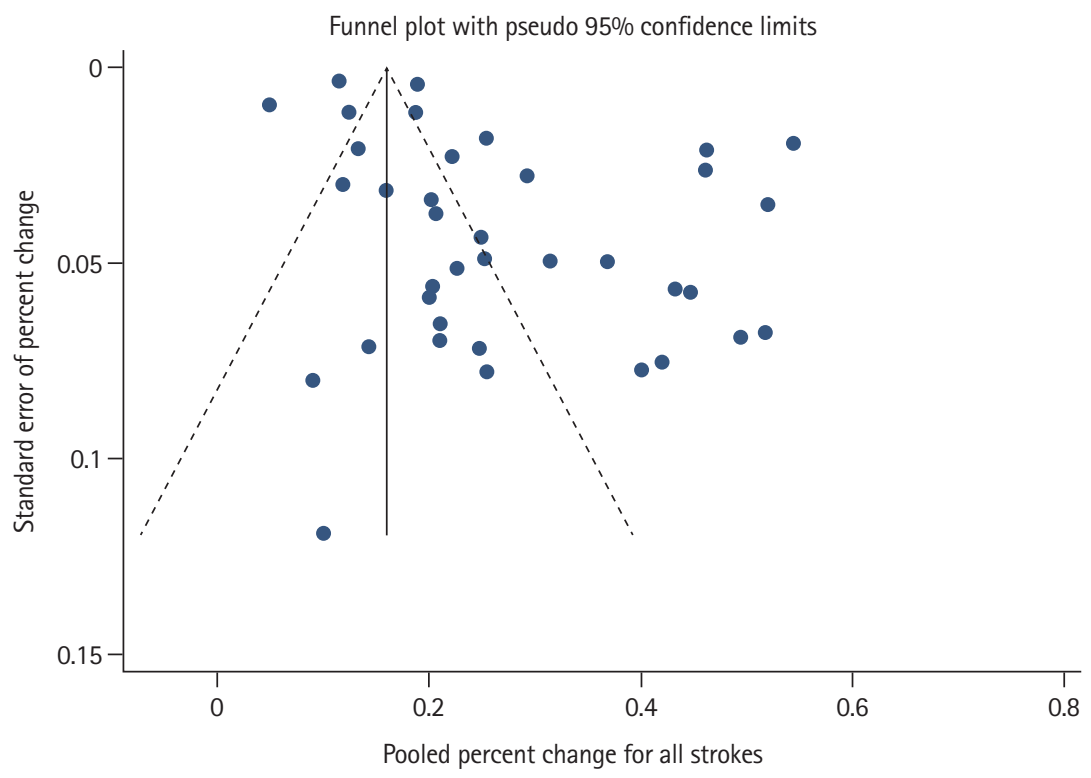

Supplementary Figure 1. Funnel plot for the meta-analysis of the percent changes in the number of all-type strokes.

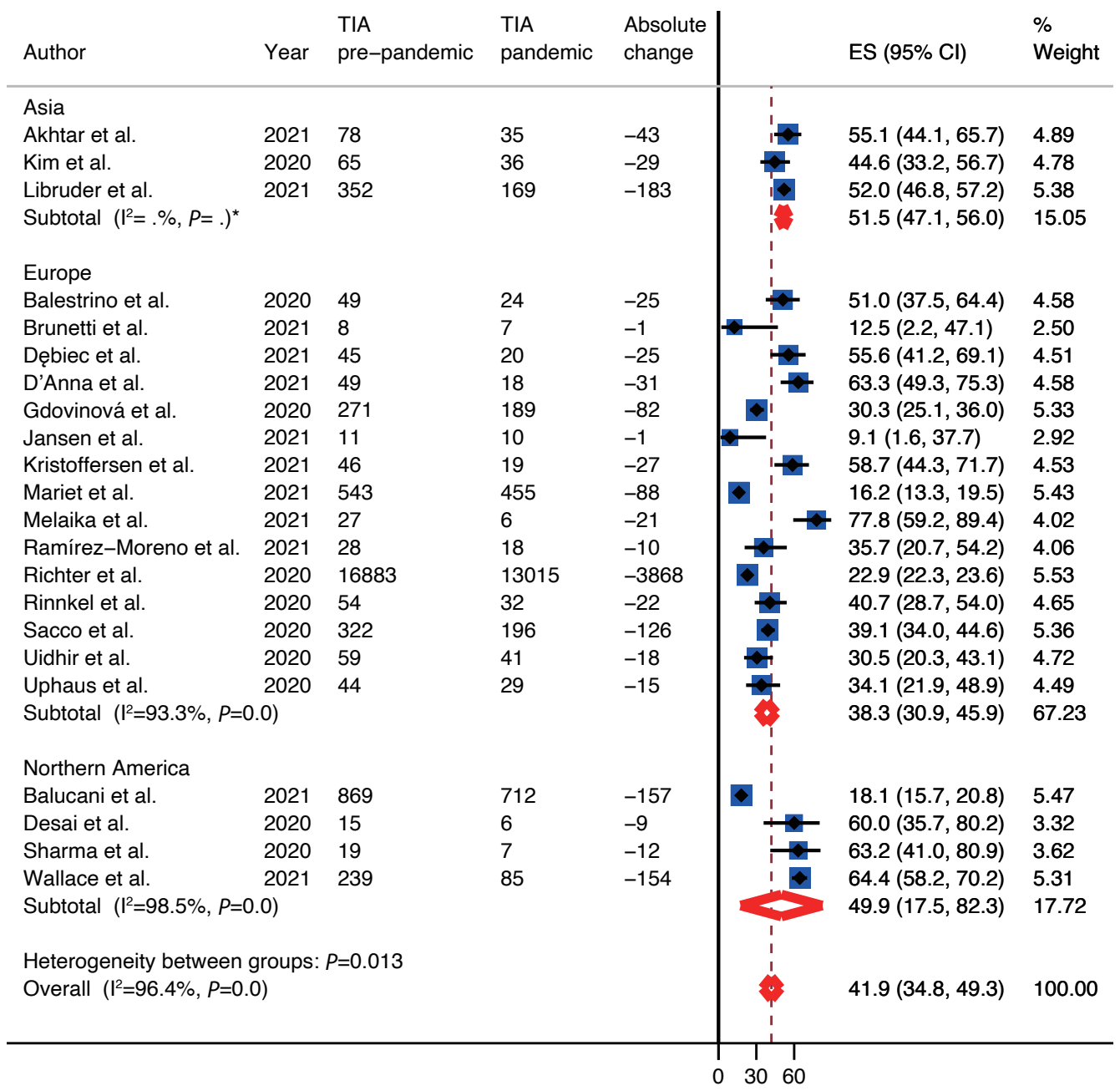

Supplementary Figure 2. Percent change in the number of transient ischemic attacks. TIA, transient ischemic attack; ES, effect size; $\mathrm{Cl}$, confidence interval. ${ }^{*}$ This statistics could not be computed due to small number of studies $(n \leq 3)$. 


\begin{tabular}{|c|c|c|c|c|c|c|c|}
\hline Author & Year & $\begin{array}{l}\text { Stroke } \\
\text { mimics } \\
\text { pre-pandemic }\end{array}$ & $\begin{array}{l}\text { Stroke } \\
\text { mimics } \\
\text { pandemic }\end{array}$ & $\begin{array}{l}\text { Absolute } \\
\text { change }\end{array}$ & & ES (95\% Cl) & $\begin{array}{l}\% \\
\text { Weight }\end{array}$ \\
\hline \multicolumn{8}{|l|}{ Asia } \\
\hline Akhtar et al. & 2021 & 262 & 102 & -160 & - & $61.1(55.0,66.8)$ & 12.79 \\
\hline Wu et al. & 2020 & 80 & 59 & -21 & 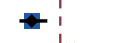 & $26.2(17.9,36.8)$ & 11.96 \\
\hline \multicolumn{5}{|c|}{ Subtotal $\left(I^{2}=. \%, P=.\right)^{*}$} & 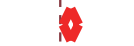 & $52.8(47.5,58.1)$ & 24.75 \\
\hline \multicolumn{8}{|l|}{ Europe } \\
\hline D'Anna et al. & 2021 & 132 & 55 & -77 & + & $58.3(49.8,66.4)$ & 12.42 \\
\hline Melaika et al. & 2021 & 164 & 83 & -81 & + & $49.4(41.8,57.0)$ & 12.56 \\
\hline Rinnkel et al. & 2020 & 115 & 77 & -38 & -1 & $33.0(25.1,42.1)$ & 12.31 \\
\hline Sacco et al. & 2020 & 531 & 345 & -186 & -1 & $35.0(31.1,39.2)$ & 13.00 \\
\hline Uidhir et al. & 2020 & 275 & 206 & -69 & 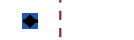 & $25.1(20.3,30.5)$ & 12.81 \\
\hline \multicolumn{5}{|c|}{ Subtotal $\left(I^{2}=92.7 \%, P=0.0\right)$} & $\otimes$ & $39.7(29.2,50.7)$ & 63.10 \\
\hline \multicolumn{8}{|l|}{ Northern America } \\
\hline Aboul Nour et al. & 2021 & 96 & 21 & -75 & + & $78.1(68.9,85.2)$ & 12.15 \\
\hline \multicolumn{8}{|c|}{ Heterogeneity between groups: $P=0.000$} \\
\hline \multicolumn{5}{|c|}{ Overall $\left(I^{2}=95.9 \%, P=0.0\right)$} & $\rightarrow$ & $45.6(33.5,58.0)$ & 100.00 \\
\hline
\end{tabular}

Supplementary Figure 3. Percent change in the number of stroke mimics. ES, effect size; $\mathrm{Cl}$, confidence interval. *This statistics could not be computed due to small number of studies $(n \leq 3)$.

\begin{tabular}{|c|c|c|c|c|c|c|c|}
\hline Author & Year & $\begin{array}{l}\mathrm{NIHSS}<5 \\
\text { pre-pandemic }\end{array}$ & $\begin{array}{l}\text { NIHSS }<5 \\
\text { pandemic }\end{array}$ & $\begin{array}{l}\text { Absolute } \\
\text { change }\end{array}$ & & ES $(95 \% \mathrm{Cl})$ & $\begin{array}{l}\% \\
\text { Weight }\end{array}$ \\
\hline \multicolumn{8}{|l|}{ Asia } \\
\hline Akhtar et al. & 2021 & 531 & 273 & -258 & 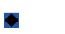 & $48.6(44.4,52.8)$ & 11.16 \\
\hline Kim et al. & 2020 & 570 & 256 & -314 & 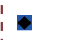 & $55.1(51.0,59.1)$ & 11.16 \\
\hline Libruder et al. & 2021 & 389 & 234 & -155 & & $39.8(35.1,44.8)$ & 11.14 \\
\hline Tavanaei et al. & 2021 & 98 & 24 & -74 & $\rightarrow$ & $75.5(66.1,83.0)$ & 10.92 \\
\hline Wu et al. & 2020 & 1075 & 468 & -607 & - & $56.5(53.5,59.4)$ & 11.18 \\
\hline \multicolumn{5}{|c|}{ Subtotal $\left(I^{2}=93.2 \%, P=0.0\right)$} & & $54.4(46.6,62.1)$ & 55.55 \\
\hline \multicolumn{8}{|l|}{ Europe } \\
\hline Brunetti et al. & 2021 & 89 & 85 & -4 & & $4.5(1.8,11.0)$ & 10.89 \\
\hline Douiri et al. & 2021 & 3157 & 2930 & -227 & & $7.2(6.3,8.1)$ & 11.20 \\
\hline Subtotal $\left(I^{2}=. \%, P=.\right)^{*}$ & & & & & & $6.9(6.0,7.8)$ & 22.09 \\
\hline \multicolumn{8}{|l|}{ Northern America } \\
\hline Ortega-Gutierrez et al. & 2020 & 636 & 412 & -224 & & $35.2(31.6,39.0)$ & 11.17 \\
\hline Wallace et al. & 2021 & 1473 & 632 & -841 & - & $57.1(54.6,59.6)$ & 11.19 \\
\hline Subtotal $\left(I^{2}=. \%, P=.\right)^{\star}$ & & & & & & $50.4(48.3,52.6)$ & 22.36 \\
\hline \multicolumn{8}{|c|}{ Heterogeneity between groups: $P=0.000$} \\
\hline Overall $\left(I^{2}=99.7 \%, P=0 . C\right.$ & & & & & & $40.2(21.7,60.2)$ & 100.00 \\
\hline
\end{tabular}

Supplementary Figure 4. Percent change in the number of mild strokes (National Institutes of Health Stroke Scale [NIHSS] $<5$ ). ES, effect size; Cl, confidence interval. *This statistics could not be computed due to small number of studies $(n \leq 3)$. 


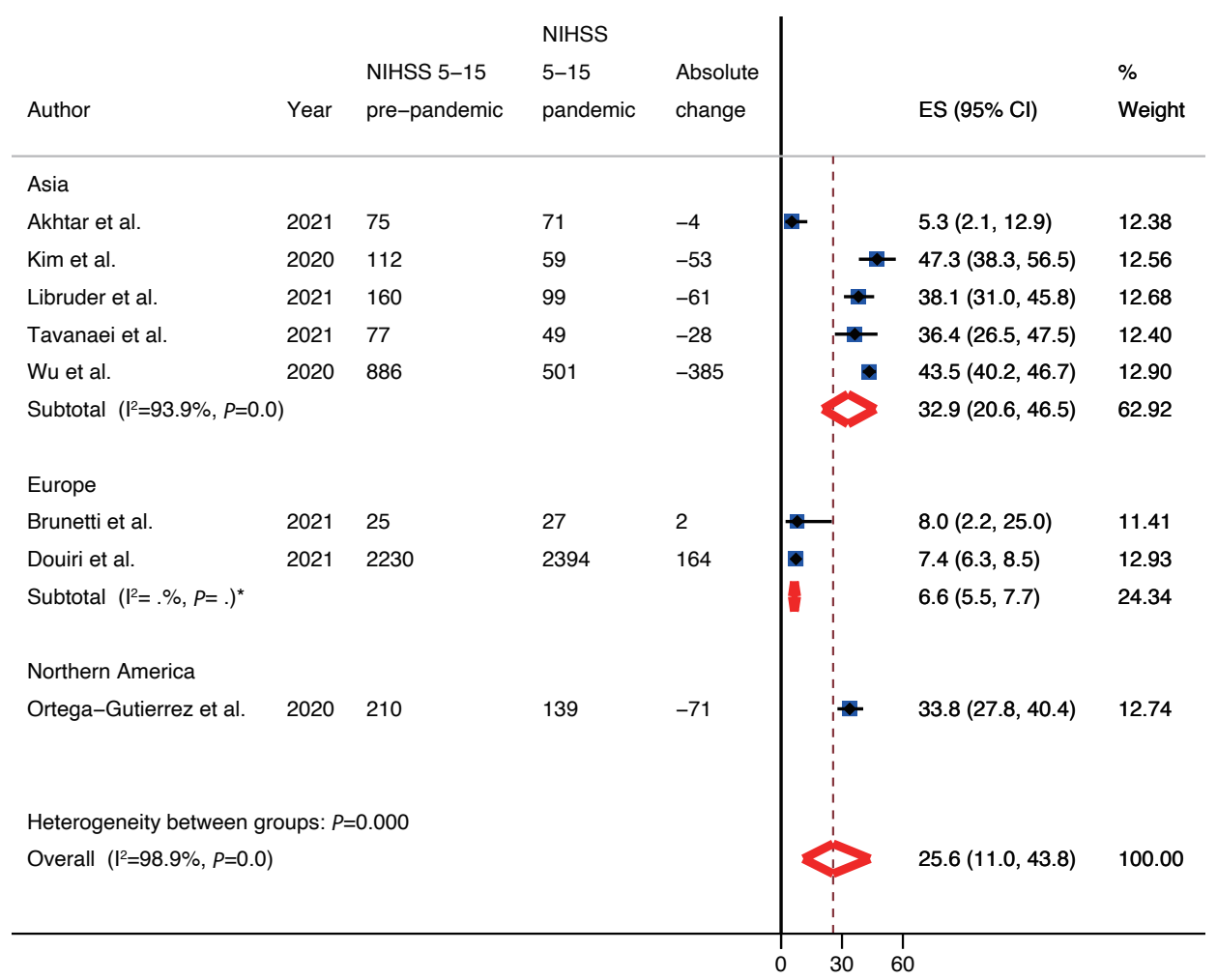

Supplementary Figure 5. Percent change in the number of moderate strokes (National Institutes of Health Stroke Scale [NIHSS] 5-15). ES, effect size; Cl, confidence interval. ${ }^{*}$ This statistics could not be computed due to small number of studies $(n \leq 3)$.

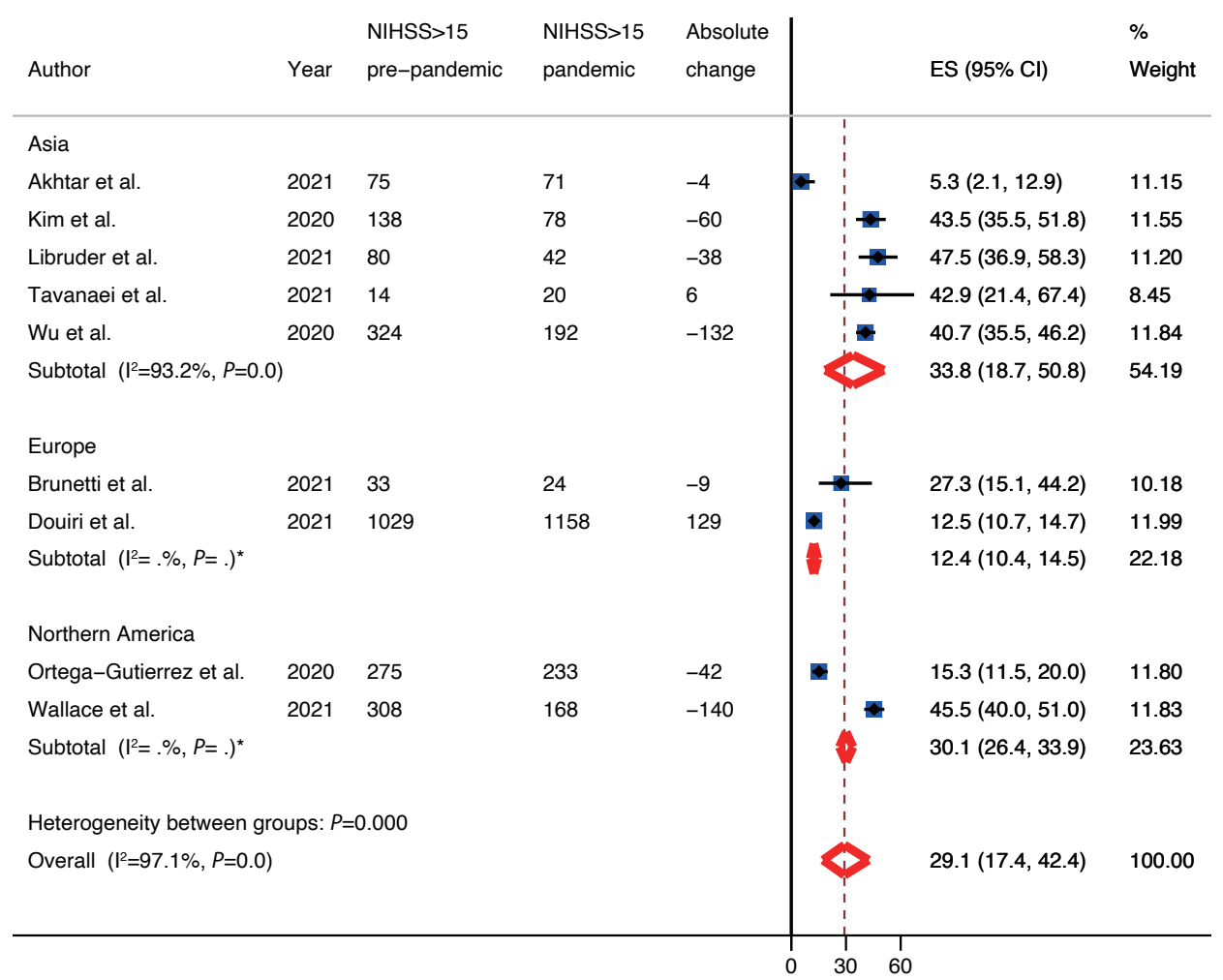

Supplementary Figure 6. Percent change in the number of severe strokes (National Institutes of Health Stroke Scale [NIHSS] >15). ES, effect size; Cl, confidence interval. *This statistics could not be computed due to small number of studies $(n \leq 3)$. 


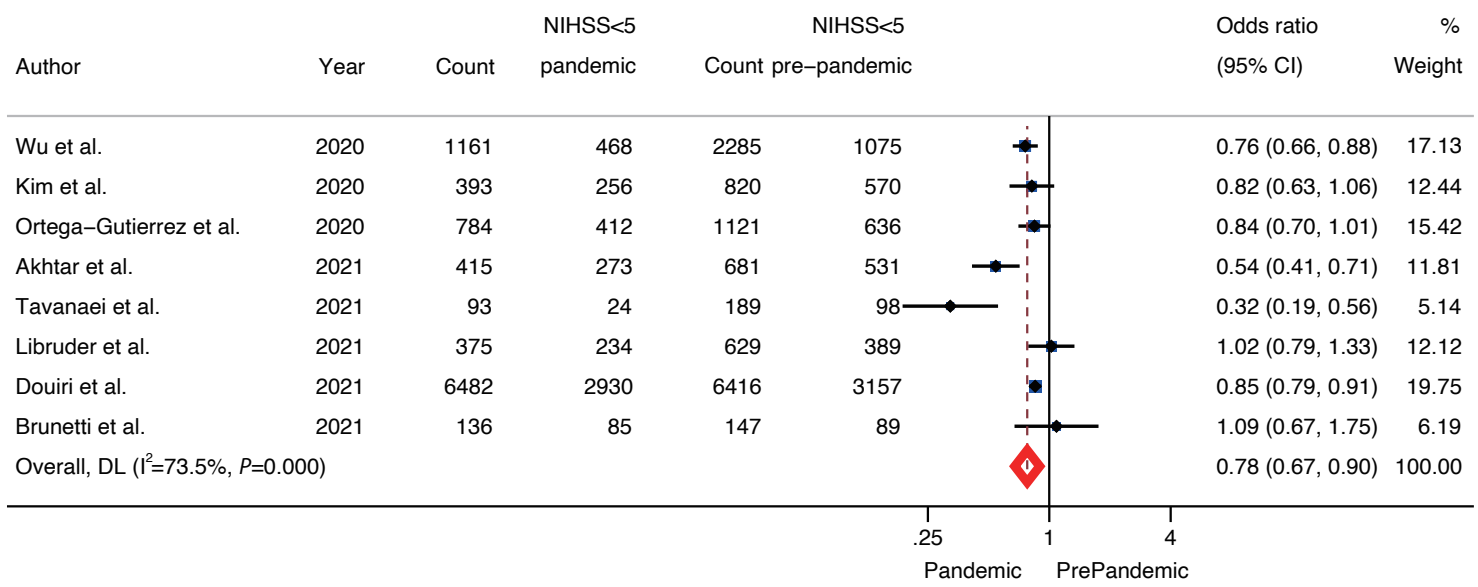

Supplementary Figure 7. Probability of having a mild stroke (National Institutes of Health Stroke Scale [NIHSS] $<5$ ). Cl, confidence interval.

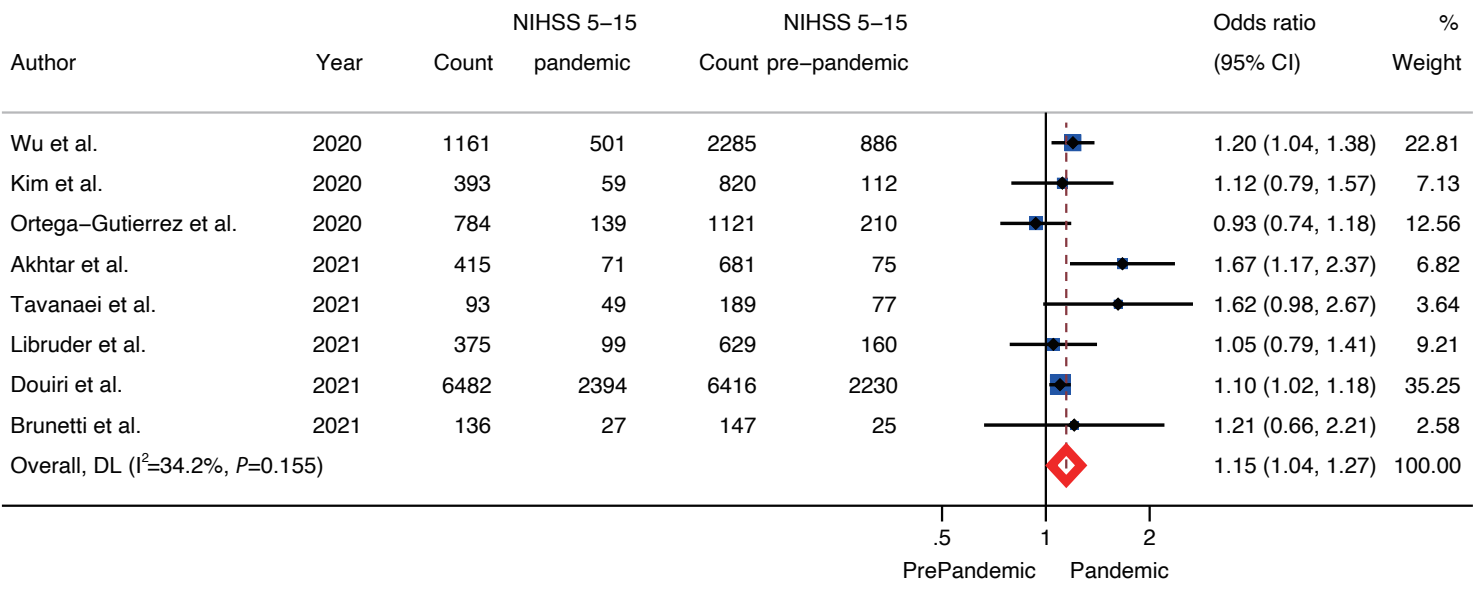

Supplementary Figure 8. Probability of having a moderate stroke (National Institutes of Health Stroke Scale [NIHSS] 5-15). Cl, confidence interval.

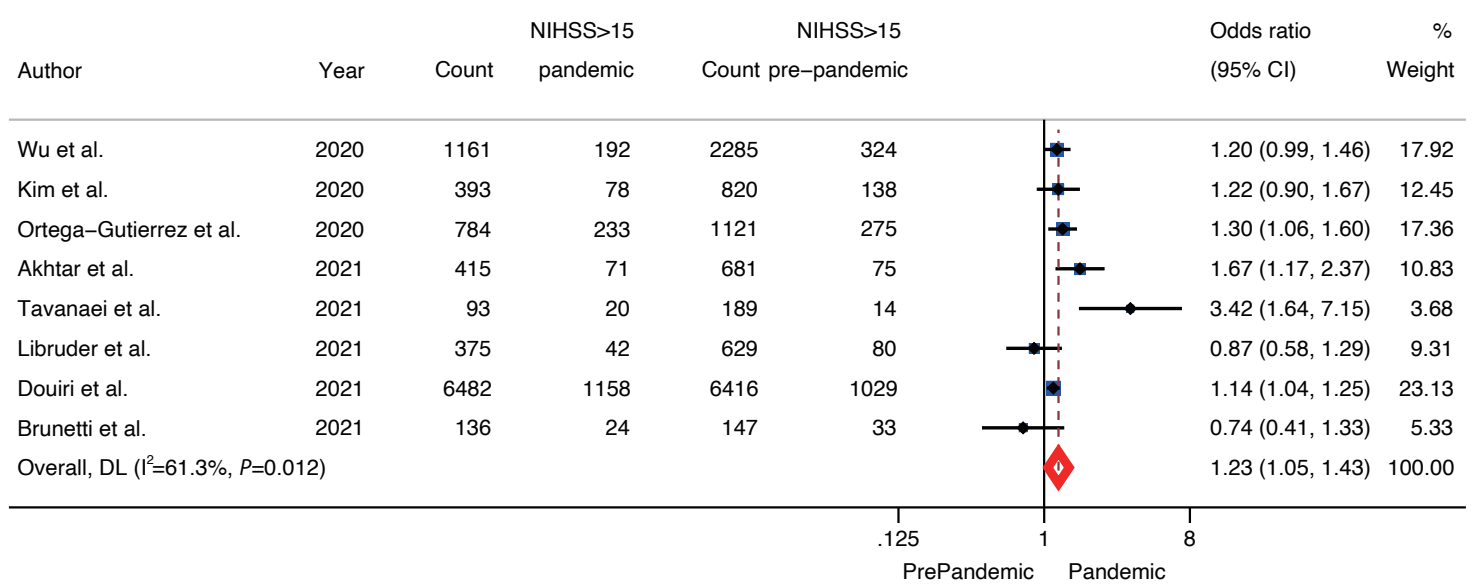

Supplementary Figure 9. Probability of having a severe stroke (National Institutes of Health Stroke Scale [NIHSS] >15). Cl, confidence interval. 


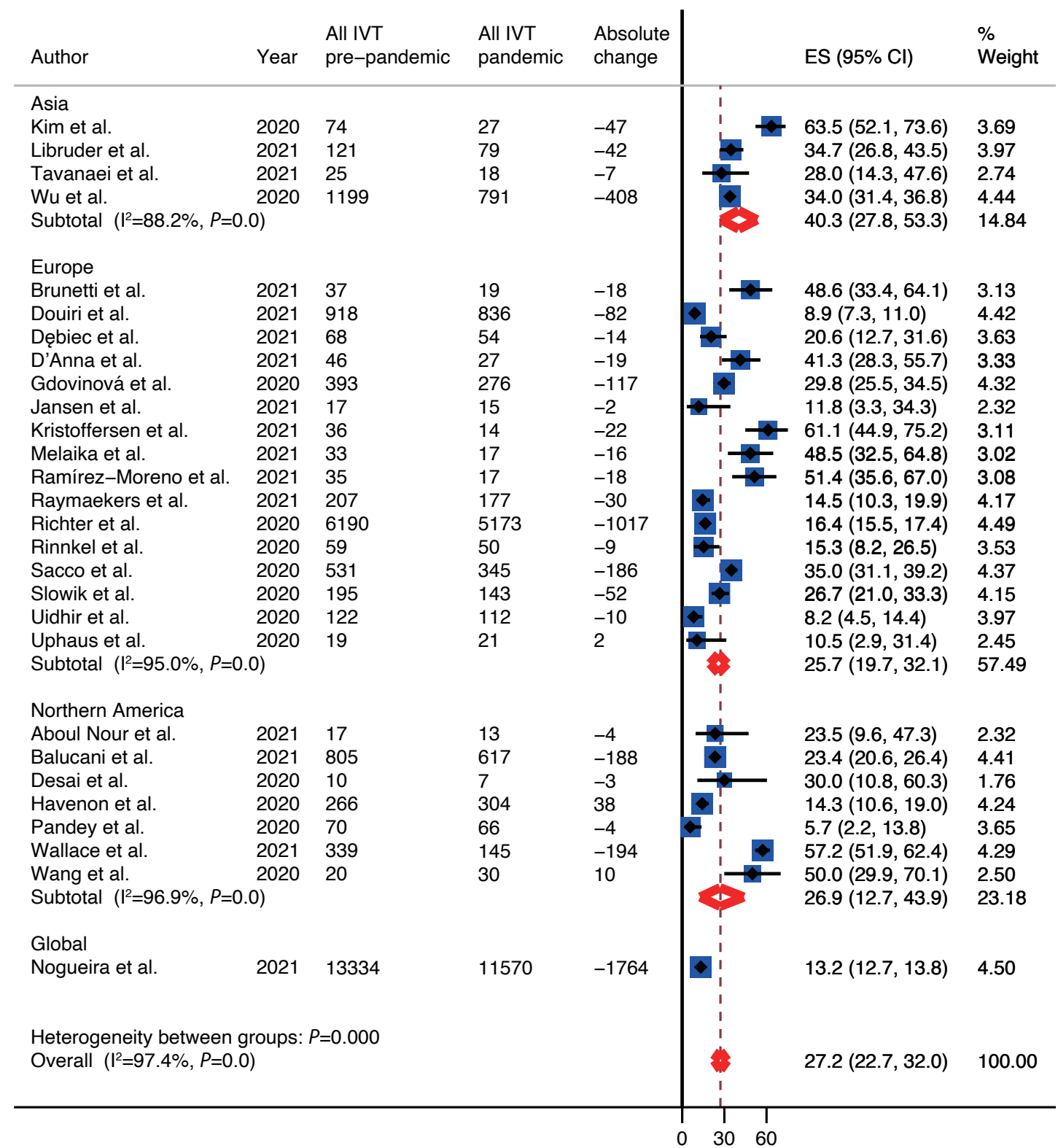

Supplementary Figure 10. Percent change in the total number of intravenous thrombolysis (IVT) performed. ES, effect size; $\mathrm{Cl}$, confidence interval. 


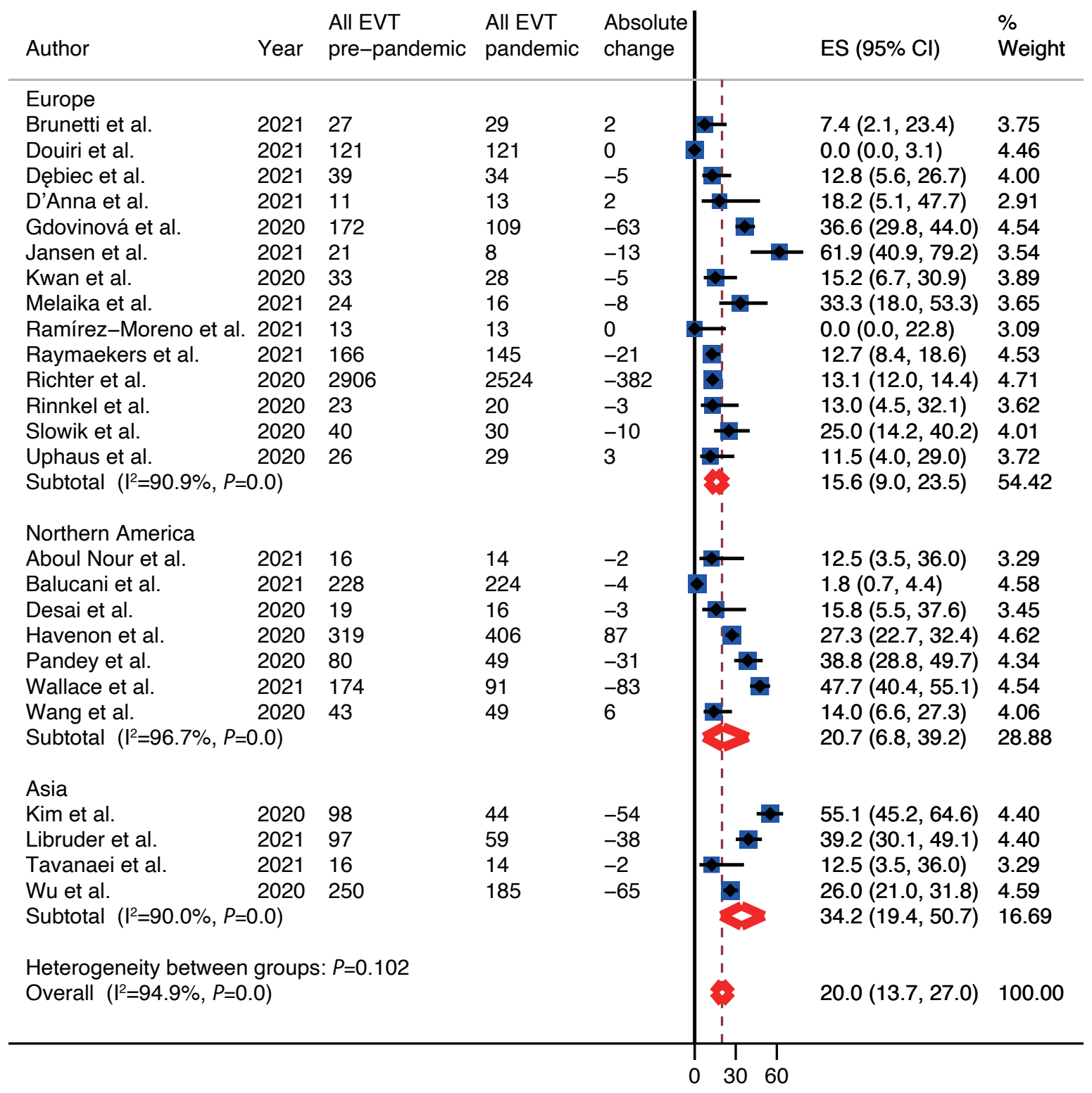

Supplementary Figure 11. Percent change in the total number of endovascular thrombectomies (EVTs) performed. ES, effect size; $\mathrm{Cl}$, confidence interval. 